\section{SANDIA REPORT}

SAND96-0902 • UC-704

Unlimited Release

Printed April 1996
RECEIVED

MAY 151996

OSTI

\title{
Radioactive Scrap Metal Decontamination Technology Assessment Report
}

Joanna M. Buckentin, Brian K. Damkroger, M. Eric Schlienger

Prepared by

Sandia National Laboratories

Albuquerque, New Mexico 87185 and Livermore, California 94550

for the United States Department of Energy

under Contract DE-AC04-94ALB5000

Approved for public release; dists 6 tition is unlimited.

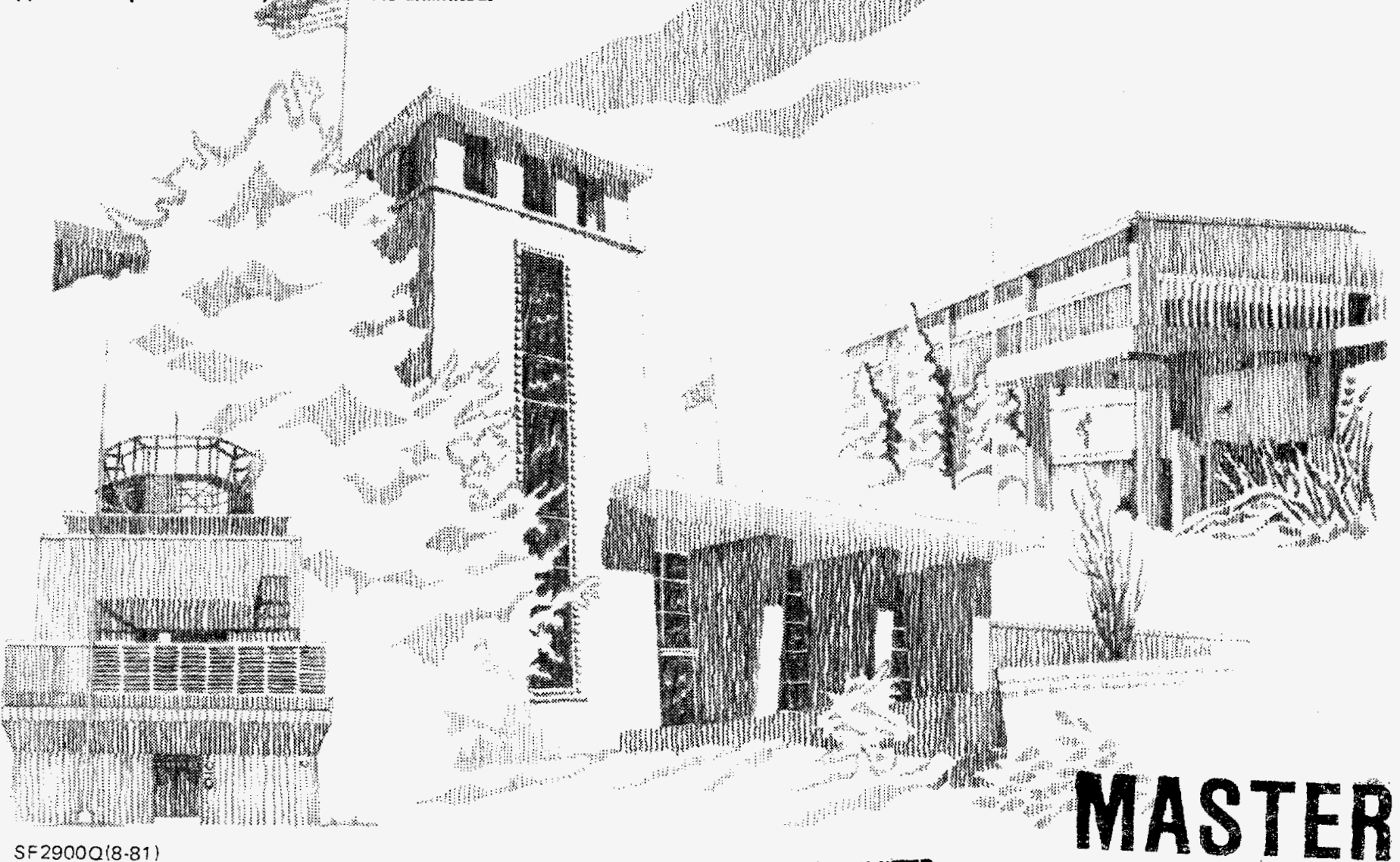


Issued by Sandia National Laboratories, operated for the United States Department of Energy by Sandia Corporation.

NOTICE: This report was prepared as an account of work sponsored by an agency of the United States Government. Neither the United States Government nor any agency thereof, nor any of their employees, nor any of their contractors, subcontractors, or their employees, makes any warranty, express or implied, or assumes any legal liability or responsibility for the accuracy, completeness, or usefulness of any information, apparatus, product, or process disclosed, or represents that its use would not infringe privately owned rights. Reference herein to any specific commercial product, process, or service by trade name, trademark, manufacturer, or otherwise, does not necessarily constitute or imply its endorsement, recommendation, or favoring by the United States Government, any agency thereof or any of their contractors or subcontractors. The views and opinions expressed herein do not necessarily state or reflect those of the United States Government, any agency thereof or any of their contractors.

Printed in the United States of America. This report has been reproduced directly from the best available copy.

Available to DOE and DOE contractors from Office of Scientific and Technical Information PO Box 62

Oak Ridge, TN 37831

Prices available from (615) 576-8401, FTS 626-8401

Available to the public from

National Technical Information Service

US Department of Commerce

5285 Port Royal Rd

Springfield, VA 22161

NTIS price codes

Printed copy: A03

Microfiche copy: A01 
7uominop

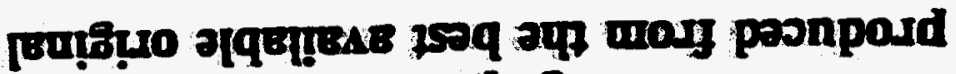
axe sestul sponpord astum syoupop o!

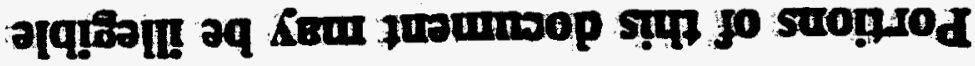

รEINTTDSTa 


\title{
Radioactive Scrap Metal Decontamination Technology Assessment Report
}

\author{
Joanna M. Buckentin, Brian K. Damkroger \& M. Eric Schlienger \\ Liquid Metal Processing Laboratory \\ Sandia National Laboratories \\ Albuquerque, NM 87185
}

\begin{abstract}
Within the DOE complex there exists a tremendous quantity of radioactive scrap metal. As an example, it is estimated that within the gaseous diffusion plans there exists in excess of 700,000 tons of contaminated stainless steel. At present, valuable material is being disposed of when it could be converted into a high quality product. Liquid metal processing represents a true recycling opportunity for this material. By applying the primary production processes towards the material's decontamination and re-use, the value of the strategic resource is maintained while drastically reducing the volume of material in need of burial. Potential processes for the liquid metal decontamination of radioactively contaminated metal are discussed and contrasted. Opportunities and technology development issues are identified and discussed.
\end{abstract}




\section{Table of Contents}

Section I - Purpose and Organization..................................... 1

I.1 Purpose of the Report........................................................1

I.2 The Basis of Rating the Technologies.............................................

I.3 Radioactive Scrap Metal - A Resource or a Liability .........................1

1.4 Contents of the Report .....................................................

I.5 Conclusions and Recommendations...........................................2

Section II - Process Descriptions.................................... 3

II.1 Surface Decontamination ............................................... 3

II.2 Size Reduction, Packaging and Burial ................................. 3

II.3 Melting Technologies .................................................. 4

Slags - The Keys to Melt Decontamination .............................4

II.4 Electric Arc Melting ........................................................4

II.5 Plasma Arc Centrifugal Treatment.............................................

II.6 Air Induction Melting ............................................................

II.7 Vacuum Induction Melting (VIM) ............................................

II. 8 Vacuum Induction Melting and Electrosiag Remelting.......................6

Section III - Summary Tables and Associated Discussions............ 7

III. 1 Sources and Types of Radioactive Scrap Metal ............................8 Table 1 - Sources and Types of Radioactive Scrap Metal................8

Discussion ............................................................ 9

III.2 Safety and Environmental Ratings of Radioactive Metal Disposition

Methods .....................................................................10

Table 2 - Safety and Environmental Ratings of Radioactive Metal

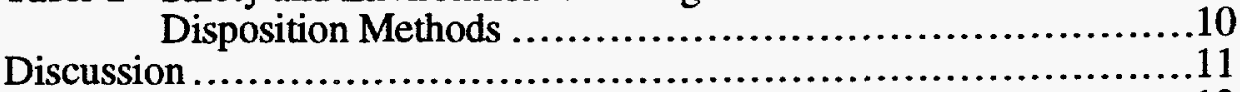

III.3 Cost Efficiency Ratings of Radioactive Metal Disposition......................13

Table 3 - Cost Efficiency Ratings of Radioactive Metal Disposition........13

Discussion ..............................................................14

III.4 Flexibility and Effectiveness Ratings of Radioactive Metal Disposition

Methods .....................................................................16

Table 4 - Flexibility and Effectiveness Ratings of Radioactive Metal

Disposition Methods ...........................................16

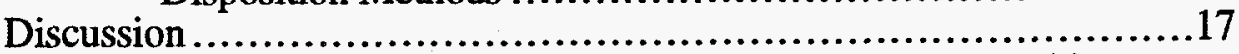

III.5 Decontamination Mechanism Ratings of Radioactive Metal Disposition

Methods .....................................................................19

Table 5 - Decontamination Mechanism Ratings of Radioactive Metal

Disposition Methods .............................................19

Discussion ...............................................................20

III.6 Experience Ratings of Radioactive Metal Disposition Methods...............21

Table 6 - Experience Ratings of Radioactive Metal Disposition

Methods....................................................21

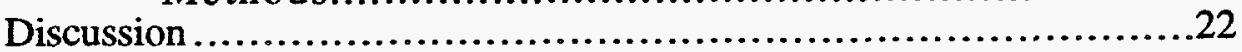

Section IV - Process Selection................................... 23

Section V - Research and Development Proposal..................... 24

V.1 Thermodynamic Modeling of Radionuclides in Slags.............................24

V.2 Solidification Studies of Slags ..........................................24

V.3 Electroslag Melting Studies with (surrogate) Contaminated Feed Stock......24 
V.4 Pilot Scale work involving Vacuum Induction Melting followed by Electroslag Remelting.

V.5 Full Scale Industrial Demonstration of Radioactive Metal Decontamination..............................................................25

V.6 Existing Assets at Sandia .............................................25

V.7 Support of Sandia's Core Competency ...................................26

Appendix 1 - A Feasibility Study of Electroslag Remelting for the Decontamination of Stainless Steel..............................27

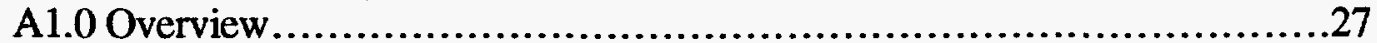

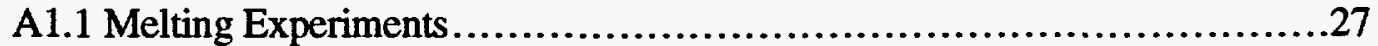

A1.2 Thermochemical Modeling ...........................................27

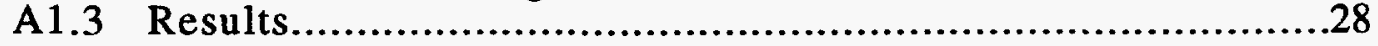

Appendix 2 - Melting as a Decontamination Process................... 29

A2.1 History of Radioactive Scrap Metal Melting .............................29

A2.2 Technology Development ................................................... 30

A2.3 Technology Utilization ................................................ 


\section{Section I - Purpose and Organization}

\section{I.1 Purpose of the Report}

The purpose of this report is to provide a summary review and evaluation of several technologies being considered for the decontamination and recycling of radioactive scrap metal. This document is also intended as a proposal for a focused research program with the goal of demonstrating an effective processing scheme. Within the US, there is a large tonnage of metal which is either slightly or highly contaminated. This metal originates from both defense related and commercial sources. Due to the initial design requirements for nuclear operations, contaminated metals tend to be high value alloys containing expensive strategic elements such as chromium and nickel. Some of the technologies reviewed approach the problem of radioactive scrap metal from a disposal viewpoint, other technologies incorporate ways to minimize the volume of radioactive waste, while others also decontaminate strategic radioactive metals so that their chemical pedigree and value as resources are retained. Decontaminated metals could be available for controlled reuse within the DOE community as opposed to being disposed of, allowing their strategic and economic value to be utilized.

Although all of the technologies reviewed have been successfully demonstrated, some of the most attractive processes require further optimization. This report contains an outline of the research required to support process scale up and design of these technologies.

\section{I.2 The Basis of Rating the Technologies}

The technologies evaluated in this report are currently available options for disposal of the growing stockpile of radioactive scrap metal in the United States. The technologies are rated with respect to their ability to meet several important criteria: process safety, environmental soundness, cost efficiency, decontamination efficiency, process flexibility (the ability of a process to successfully handle different types and amounts of metals and contaminants), and the ability of a process to maintain the characteristics and performance of the original material. Finally, the experience base available to support research, development, and scale up of those processes with the highest potential is discussed.

\section{I.3 Radioactive Scrap Metal - A Resource or a Liability}

As an example, it has been estimated that there exists 700,000 tons of contaminated stainless steel in the gaseous diffusion plants. Assuming a commercial (non-subsidized) disposal cost of $\$ 450$ per cubic $\mathrm{ft}$. and a packing density equivalent to 2 inch pipe, the disposal cost of this material is approximately $\$ 10$ per pound. Therefore, this stainless steel may represent a disposal liability on the order of $\$ 14,000,000,000$. Conversely, in the form of sheet, this stainless steel has a value of about $\$ 3$ per pound. Assuming a $\$ 1$ per pound decontamination and conversion cost, then this same material could represent a net asset of $\$ 2,800,000,000$. Even allowing for significant variations in disposal costs, the material value recovered resulting from the recycling of this valuable stainless steel resource, as opposed to burial, represents a savings of several billion dollars. 


\section{I.4 Contents of the Report}

This report contains the following sections:

Section I Report Purpose and Organization.

Section II Descriptions of each process and its application as a decontamination strategy.

Section III Summary tables and associated discussions comparing the technologies with respect to:

- $\quad$ Process Safety and Environmental Concerns

- Cost Efficiency

- Process Flexibility and Effectiveness

- Decontamination Mechanism

Section IV Identification of processes with the highest potential for use in the decontamination of radioactive metal.

Section V Research and development steps necessary to evaluate, optimize, and demonstrate the most attractive technologies, and a description of a development program and capabilities which will allow efficient completion of this research.

Appendix 1 Overview of a feasibility study performed at Sandia. The goal of the study was to characterize one melt decontamination strategy with respect to changes in process parameters. A thermodynamic model was developed and used to interpret the results.

Appendix II A literature survey of melting as a decontamination process. This section provides summary reviews of laboratory scale research and development studies which have led to the implementation of various melt decontamination strategies around the world.

\section{I.5 Conclusions and Recommendations}

- There is a large amount of radioactive contaminated metal present in the DOE complex. This metal represents a huge liability if it must be cut, compacted, and buried, but a tremendous resource if it can be utilized.

- Liquid metal processing, if optimized and developed, offers the possibility of decontaminating this metal by accessing a range of separation mechanisms. It offers the ability to retain the pedigree and inherent value of the material, to operate at a realistic scale, and to produce useful output products, subject to controlled use within the DOE community.

- Further work must be done, however, to research the mechanisms involved in and to optimize the performance of potential decontamination processes. 


\section{Section II - Process Descriptions}

This section provides an overview of the various processes which are currently used for the decontamination of radioactive scrap metal or alternatively show considerable promise for the treatment of this material. The descriptions are not intended as an in depth review, rather, they are included to provide a general overview sufficient to allow a reasonable comparison.

\section{II.1 Surface Decontamination}

Surface decontamination can be affected by either mechanical (sand blasting), chemical (acid attack), or electrochemical (anodic dissolution) removal of radioactive contaminants from the surfaces of metal parts or structures. These methods are inexpensive, uncomplicated, and relatively effective for the removal of surface contamination of parts with simple geometries. Surface decontamination may provide partial decontamination of piping assemblies without the need for disassembly. However, these techniques do nothing to remove bulk contamination and are ineffective for complex geometries, or for removal of contamination from cracks, a common flaw in reactor steam and heat exchanger tubes. Since these methods employ the principle of physical or chemical scouring to remove contamination, they result in a contaminated waste stream of scouring agent such as water, acid, or a sand slurry. The creation of this secondary waste stream creates further handling and disposal problems.

\section{II.2 Size Reduction, Packaging and Burial}

As currently being performed, this option only requires that pieces of radioactive metal be torch cut or consolidated by melting to sizes small enough to fit within a waste container. When full, these containers are sealed and permanently stored in a monitored repository. While this method of scrap metal disposal is inexpensive under current government policies, and may be performed with relative ease, this option is becoming increasingly unacceptable when long term costs and environmental factors are considered. However perhaps the most compelling reason for avoiding burial lies in the wealth of strategic alloying elements contained in radioactive scrap metal. As shown in the charts below, America's stockpile of radioactive scrap metal represents the largest domestic resource for elements such as nickel, chromium, and manganese. Unless decontaminated and recycled, this resource is lost.

\begin{tabular}{|c|c|c|c|}
\hline Strategic Element & Chromium & Nickel & Manganese \\
\hline Uses & $\begin{array}{l}\text { Present in the } 18- \\
20 \% \text { range to inhibit } \\
\text { corrosion in stainless } \\
\text { steel. }\end{array}$ & $\begin{array}{l}\text { Base for Inconel and } \\
\text { other nickel base } \\
\text { alloys }\end{array}$ & $\begin{array}{l}\text { Alloying element in } \\
\text { steel production }\end{array}$ \\
\hline $\begin{array}{l}\text { Sources of } \\
\text { Virgin Material }\end{array}$ & $\begin{array}{l}\text { South Africa } \\
\text { Former Soviet } \\
\quad \text { Union } \\
\text { Turkey } \\
\text { Rhodesia } \\
\text { Philippines } \\
\text { Cuba } \\
\text { Yugoslavia }\end{array}$ & $\begin{array}{l}\text { Canada } \\
\text { New Caledonia } \\
\text { Former Soviet } \\
\quad \text { Union } \\
\text { South Africa } \\
\text { Burma } \\
\text { East Indies }\end{array}$ & $\begin{array}{l}\text { Ukraine } \\
\text { South Africa } \\
\text { India } \\
\text { Ghana }\end{array}$ \\
\hline
\end{tabular}




\section{II.3 Melting Technologies}

Melt decontamination of radioactive scrap metal has been widely studied, both in the US and abroad, as detailed in Appendix II. Melt decontamination has several inherent advantages. Melt decontamination processes operate above the melting point of the scrap metal so that decontamination reactions take place either between two liquid phases or between a liquid phase and a gas phase. The high temperature at which these processes operate aids their kinetic efficiency and makes the involved reactions very rapid. When the radionuclide to be removed has a higher vapor pressure than its host metal, melting technologies can take place under vacuum in order to facilitate the removal of these species. Some melting technologies support the use of slags or fluxes (molten mixtures of oxides immiscible in liquid metal, further described in the text box below) which interact thermochemically and electrochemically with the liquid metal to specifically capture radionuclides. When properly formulated, these slags act as a low volume, stable containment for radioactive species.

Each process described below has been used industrially for the melt processing of non-radioactive materials. In this section, various melting techniques are described in terms of their process design and its implications for radioactive scrap remelting.

\section{Slags - The Keys to Melt Decontamination}

\begin{tabular}{|l|l|}
\hline What are they? & $\begin{array}{l}\text { Slags are mixtures of molten oxides such as } \\
\mathrm{Al}_{2} \mathrm{O}_{3}, \mathrm{CaO} \text {, or SiO }, \text { and fluorides such as } \\
\mathrm{CaF}_{2} \text {. When solidified the slags are solid } \\
\text { synthetic minerals. }\end{array}$ \\
\hline What do they do? & $\begin{array}{l}\text { Slags interact with liquid metal, capturing } \\
\text { radioactive species, incorporating the } \\
\text { radionuclides into the stable structure of the } \\
\text { solidified slag. }\end{array}$ \\
\hline How do they do it? & $\begin{array}{l}\text { Many radionuclides form thermodynamically } \\
\text { stable oxides. Liquid slag supplies the } \\
\text { oxygen in a readily available form. Stable } \\
\text { oxides, such as UO, and are then captured } \\
\text { within the slag. }\end{array}$ \\
\hline $\begin{array}{l}\text { What does their efficiency } \\
\text { depend on? }\end{array}$ & $\begin{array}{l}\text { The rate of chemical reactions is time and } \\
\text { temperature dependent, but other factors are } \\
\text { important. Slags can be chemically optimized } \\
\text { in order to capture specific radionuclides } \\
\text { while leaving strategic alloying elements in } \\
\text { the metal. Also, in melting processes which } \\
\text { pass a current through the slag (Electroslag } \\
\text { remelting), electrochemical mechanisms can } \\
\text { be utilized as well. }\end{array}$ \\
\hline
\end{tabular}

\section{II.4 Electric Arc Melting}

In Electric Arc Melting, the charge is heated and melted due to an arc passing between an electrode and the charge (in direct current melting) or indirectly between three electrodes (in three phase alternating current). Electric arc furnaces consist of a refractory lined hearth and a water cooled roof section containing holes allowing the electrodes to be lowered into position. The roof section may be lifted or swung away to permit the loading 
of feed stock into the furnace. The roof section is then replaced, the electrodes are lowered and power is applied to melt the charge. After melting, the furnace is tilted and the molten metal is poured into a ladle. This process produces a great deal of dust and fume. Due to the logistics of scrap loading and molten metal removal, these furnaces are difficult to enclose.

In order to safely use Electric Arc Melting as a decontamination strategy, measures must be taken to capture and contain volatile elements and dust. In addition, spent refractory from the furnace hearth and from ladles used to transport molten metal becomes a radioactive waste stream. Slag handling is complex, because radioactive slags must be handled in a molten condition, at or above 1400 degrees C. British Steel Corporation conducted a study to determine the practicality of releasing properly treated and characterized radioactive scrap metal to commercial electric furnace operations. The scrap used in this study was composed of contaminated steel from three different reactor systems. Ten heats were melted in a 5 tonne electric arc furnace. The radionuclides of interest were ${ }^{60} \mathrm{Co},{ }^{134} \mathrm{Cs}$, and ${ }^{137} \mathrm{Cs}$. Because of its chemical similarity to iron, the cobalt partitioned to the steel castings while the cesium was captured in the slag and the fume. The conclusion drawn from this research was that, although the process could be operated within the published safety criteria, the cost of controlling and monitoring the scrap would outweigh its value. In France, a 15 tonne electric arc furnace has been used since April 1992 for the consolidation and treatment of ferrous materials recovered from the dismantling of the $\mathrm{CO}_{2}$ systems from the graphite moderated, $\mathrm{CO}_{2}$ cooled, plutonium production and power generation reactors at Marcoule.

\section{II.5 Plasma Arc Centrifugal Treatment}

The Plasma Arc Centrifugal Treatment process utilizes a high temperature plasma as a means of melting material in a rotating ceramic lined tub and is conducted within a fully enclosed environment. As such, operator exposure to potentially toxic material is limited. Operator exposure is further reduced by the processes ability to handle a wide array of feed materials, thereby reducing feed stock handling. During processing, the waste is delivered into the rotating tub and the rotational motion distributes the plasma energy around the interior. When the tub becomes full, the rotation is slowed, and the molten material pours out through a hole in the center of the tub. The process has been demonstrated as being able to process entire 55 gallon drums of mixed waste. The high temperatures and oxidizing capability allow a wide range of wastes to be successfully processed. The resultant material is a glassy non-leaching synthetic mineral. Although Plasma Arc Centrifugal Treatment is an ideal process for pacification and waste disposal, it does not effectively recover the valuable metallic feed stocks.

\section{II.6 Air Induction Melting}

An induction furnace is an $\mathrm{AC}$ electric furnace in which the primary conductor is cooled and generates, by electromagnetic induction, a secondary current that develops heat within the metal charge. Once the charge is molten, this current may also be used to stir the melt. Induction melting permits, but does not require the use of a slag. Induction furnaces are refractory lined, so reactions between the refractory and the metal, and the refractory and the slag will occur. Such reactions may cause the presence of refractory particles in the melt. Molten slag is removed by skimming, often manually. Because these furnaces may be opened for molten slag removal, sealing them is difficult and fumes and dust will escape during the slag skimming process. Induction furnaces favor good melt agitation, relatively easy fume control, and rapid heat up, making consolidation and homogenization of scrap charges efficient. Induction melting is not inherently as dusty a process as Electric Arc 
Melting. For example, an induction furnace produces only $20 \%$ as much effluent dust as an electric arc furnace of similar capacity. When used as a melt decontamination strategy, the overall process must include plans for capture of those radionuclides $\left({ }^{137} \mathrm{Cs}\right)$ which will report to the fume and dust. Additionally, plans must be made for disposal of contaminated furnace and ladle refractory and for the solidification and containment of spent slag. Facilities for the induction melting of radioactive scrap metal have been constructed and are being used in Sweden, Germany, and Japan. In the United States, SEG (Scientific Ecology Group) operates a 20 ton, $7200 \mathrm{~kW}$ induction melting furnace equipped with a dedicated fume hood. The furnace operates within a building equipped with HEPA filtered ventilation. Radioactive scrap metal treated in this furnace is used to produce shielding blocks for nuclear operations.

\section{II.7 Vacuum Induction Melting (VIM)}

Vacuum Induction Melting is based on the same principle as Air Induction Melting, except that melting is performed in a sealed chamber and under a vacuum. This design facilitates the capture of dust and fume. When performed in a vacuum, induction melting does not usually incorporate a slag layer. Vacuum Induction Melting is an optimum decontamination strategy for the removal of volatile radionuclides, but does not permit the removal of non-volatile radioactive species.

\section{II.8 Vacuum Induction Melting and Electroslag Remelting}

Vacuum Induction Melting is an excellent process for the consolidation of scrap and the removal of volatile elements from molten metal. However, it is ineffective for the removal of nonvolatile elements, or for the removal of nonmetallic particles from the bath. For these reasons, Vacuum Induction Melting is most attractive when performed in tandem with another melting process, Electroslag Remelting or ESR. ESR is a consumable electrode process in which heat is generated by the passage of electric current through a conductive slag, which is resistively heated. As the electrode melts, the droplets of metal are refined by contact with the slag. The droplets collect at the bottom of a water cooled copper crucible and consolidate to form an ingot with low residual impurities, very few nonmetallic inclusions, and excellent surface quality. ESR produces a metal shape which may be directly formed into a useful product. The combination of Vacuum Induction Melting and Electroslag Remelting has several strengths when used as a decontamination strategy. During the VIM step, the volatile radionuclides are removed from the metal, which is cast into an electrode to be used as feed stock for the ESR process. During the ESR process, many decontamination mechanisms come into play. Radionuclides may be transferred from metal to slag at three sites: at the molten metal/slag interface present at the electrode tip, at the metal droplet/molten slag interface, and at the interface between the not yet solidified ingot and the slag. In addition, due to the presence of an electric current, two of these surfaces are electro-active, and the flow of electrons may be used to optimize decontamination reactions. At the completion of melting, the slag containing the radionuclides is removed as a solid, which is much easier and safer than the handling of liquid slag required by other processes. Further, the combination VIM/ESR process is the process which is currently used to produce many commercial alloys and as such fully maintains or enhances the value of the input material. Appendix I provides details of a pilot scale study performed at Sandia to study the effectiveness of the ESR process for removal of surface contamination from stainless steel. 


\section{Section III - Summary Tables and Associated Discussions}

The following tables are designed to provide a straightforward mechanism for the evaluation and comparison of issues and techniques associated with the recycling of radioactive stainless steel. A total of six tables are provided. Following each table is a brief discussion on the meaning of the table and the rationale behind the ratings. 


\section{Sources and Types of Radioactive Scrap Metal}

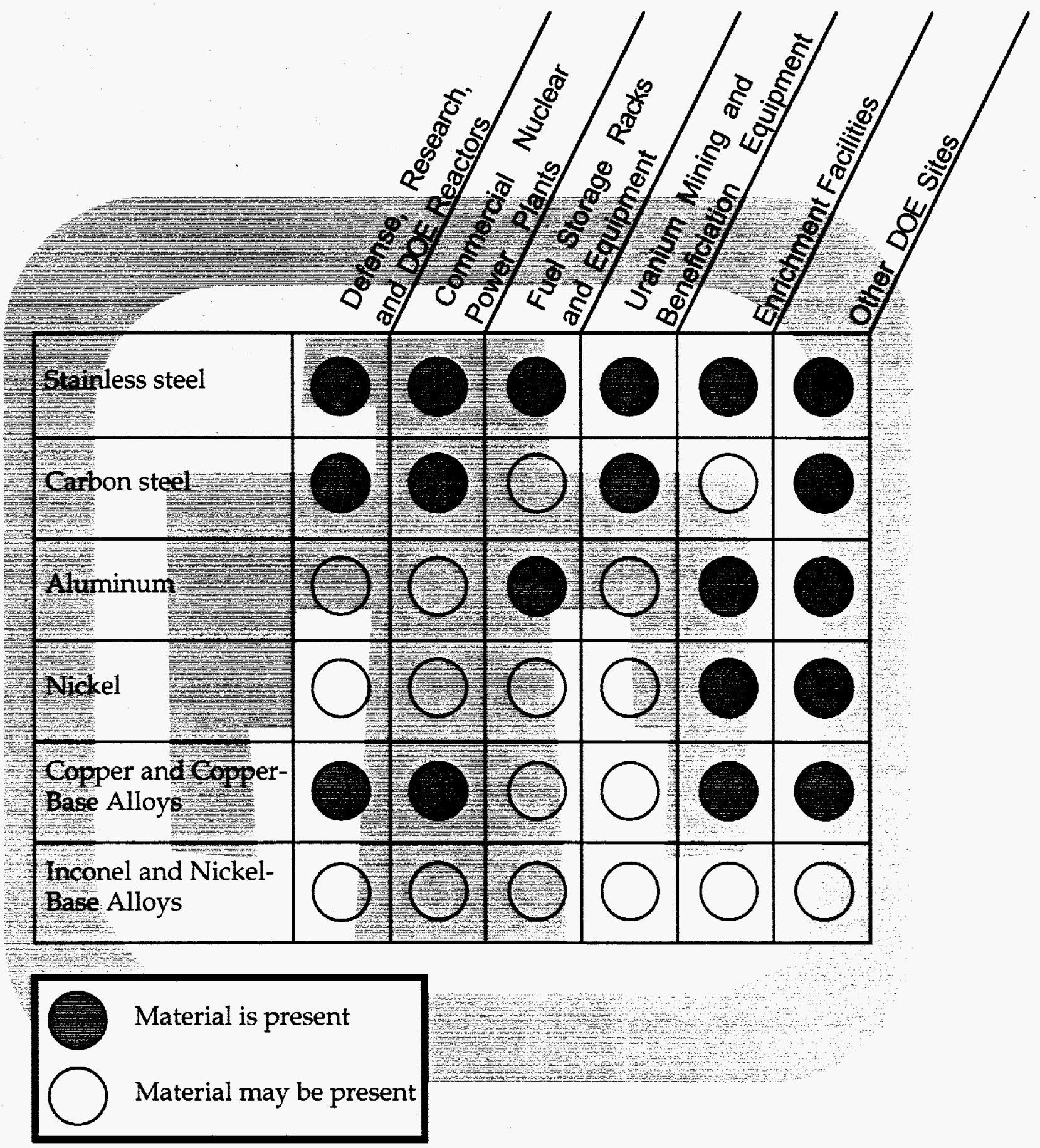




\section{Sources and Types of Radioactive Scrap Metal}

The table depicted on the previous page is provided in order to illustrate the many forms and sources of radioactive scrap metal. For example, reductions in weapons programs are a source of radioactive scrap metal, and as various facilities designed for the processing of radioactive material are shut down, the stock pile of contaminated material continues to grow. An additional source of scrap is associated with commercial nuclear power reactors. As these reactors reach and exceed their forty year expected lifetime, many are being shut down. Cleanup of these reactors is a problem since many of their components tend to be large and composed of high strength metallic materials. At present, the contaminated material takes many forms; types of metal included in the growing radioactive scrap metal stockpile include, but are not limited to:

- $\quad$ Stainless Steel

- Carbon Steel

- Aluminum

- Nickel

- Inconel and other Nickel Base Alloys

- Copper and other Copper Base Alloys

The sources of these radioactive metals include:

- Defense, Research, and DOE Reactors

- Commercial Nuclear Power Plants

- $\quad$ Fuel Storage Racks and Associated Equipment

- Uranium Mining and Beneficiation Equipment

- Uranium Enrichment Facilities, and

- $\quad$ Other DOE Sites.

The table shows that many different types of contaminated metals may be present at any one location. Any decontamination technology chosen, therefore, should be flexible enough to be able to treat more than one type of metal. It should also be noted that stainless steel represents the greatest volume of radioactively contaminated metal, and is present to a greater or lesser degree at virtually every site where radioactive materials are handled or processed. Research focused on the decontamination of stainless steel is important because it addresses material which comprises the bulk of the stockpile. 
Safety and Environmental Ratings of Radioactive Metal Disposition Methods

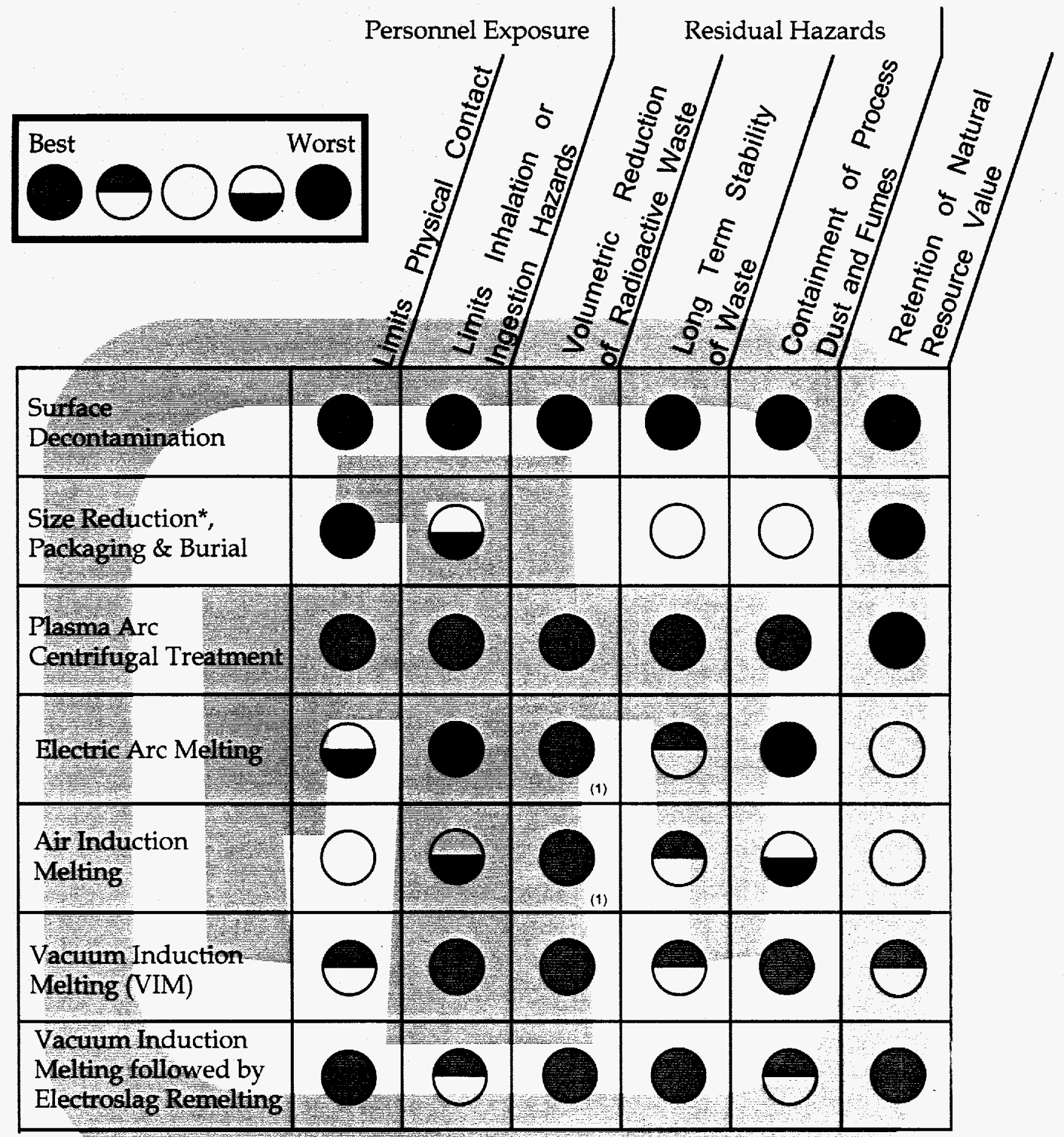

*Mechanical or Melt Reduction.

(1) Assumes technology $/$ regulatory environment will permit metal to be classified as decontaminated 


\section{Safety and Environmental Ratings of Radioactive Metal Disposition Methods}

The table depicted on the previous page is provided in order to compare the evaluated radioactive metal disposition methods. Several rating criteria have been assembled to assess process safety and environmental issues. These rating criteria are:

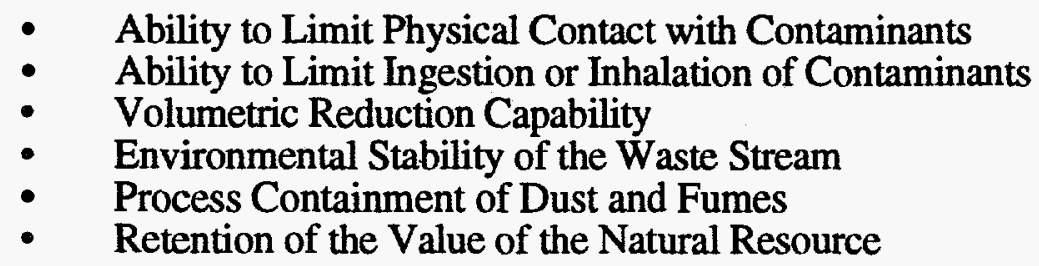

For this table, the comparison of these technologies is based upon the potential degree of personnel exposure and environmental risk. The process of Surface Decontamination is unfavorable because it produces a contaminated liquid waste stream which is difficult to contain, may produce fumes and is often corrosive. In a worst case scenario, this liquid could soak through radiation suits and clothing to make direct skin contact. Size Reduction, Packaging and Burial was ranked unfavorably because of the necessity of manually torch cutting the scrap into pieces, followed by the repeated contact necessary to catalogue and sort the pieces into containers. Plasma Arc Centrifugal Treatment avoids exposure, as feed stock can be contained in drums and the process is completely enclosed. Electric Arc Melting furnaces require finely divided scrap to avoid electrode damage and as such require substantial feed stock preparation. In addition, this process generates a great deal of dust and fume. Air Induction Melting generates about $20 \%$ of the dust generated by Electric Arc Melting, but still requires size reduction of scrap. Vacuum Induction Melting avoids much personnel exposure because the melting furnace is completely enclosed. Some scrap preparation is required and the ingot produced is not completely free of radionuclides. When Vacuum Induction Melting is followed by Electroslag Remelting, exposure risks are low because the scrap metal is reduced to a monolithic, decontaminated ingot.

When the technologies are compared on the basis of residual hazards, the process of Surface Decontamination is unfavorable because it produces a large volume of contaminated liquid, which must be treated and this residue must be stored. Additionally, the metal may be incompletely decontaminated due to the presence of adhesive residue present in cracks. The metal then must be cut up, packaged, and placed in storage. Size Reduction, Packaging and Burial reduces the volume of the metal only in the sense that its compactness is increased. The packaged waste is moderately stable provided the storage containers are not breached. Plasma Arc Centrifugal Treatment, being a melting treatment, produces an ingot that is completely dense and very stable. Because the process is completely enclosed, capture and containment of process dust is facilitated. Electric Arc Melting also renders the metal completely dense, but as by product produces contaminated waste in the form of spent refractory, slag, and process dust. Air Induction Melting produces a completely dense ingot and a somewhat lesser amount of spent refractory. Vacuum Induction Melting ranks better because the vacuum enclosure lends itself to the containment of process dust. When Vacuum Induction Melting is followed by Electroslag Remelting, spent refractory from the vacuum induction furnace can be recycled as ESR slag and thus rendered completely dense and stable. 
A most important basis of comparison is the ability of each process to retain the value of the metal being treated. This aspect represents a twofold savings. The first set of savings are realized in the avoidance of throwing away valuable material. The second group of savings are associated with the limited strategic resource as represented by the alloying elements in the material, and by avoiding the environmental impact inherent in mining a dwindling stock of mineral resources. Since these metals are high value alloys, processes which enable the decontamination and reuse of the metal rank higher than those which do not. Thus, Surface Decontamination and Size Reduction, Packaging and Burial rank unfavorably because the material is not available for reuse. Plasma Arc Centrifugal Treatment produces a product which is not fully decontaminated. Electric Arc Melting and Air Induction Melting do a better job of decontamination, but ingots produced will contain large numbers of nonmetallic inclusions, which may contain contamination and will have a detrimental effect on the material properties. Vacuum Induction Melting is not, by itself, a complete decontamination process, but when Vacuum Induction Melting is followed by Electroslag Remelting, a decontaminated ingot is produced which has physical properties equal to or better than those of the original material. 
Cost Efficiency Ratings of Radioactive Metal Disposition

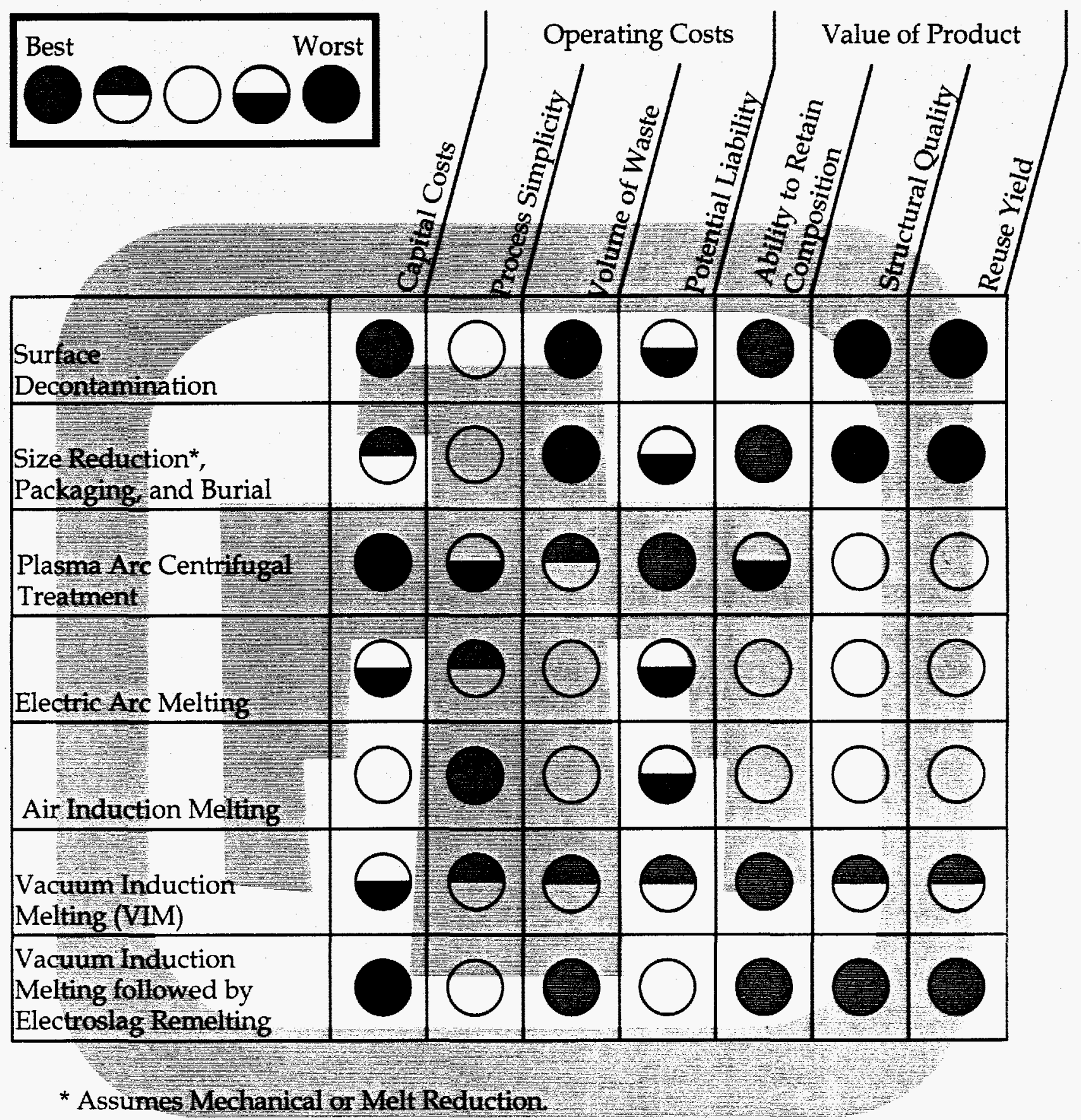




\section{Cost Efficiency Ratings of Radioactive Metal Disposition Methods}

The table depicted on the previous page compares several radioactive metal disposition methods with respect to Cost Efficiency. The specific categories examined are:

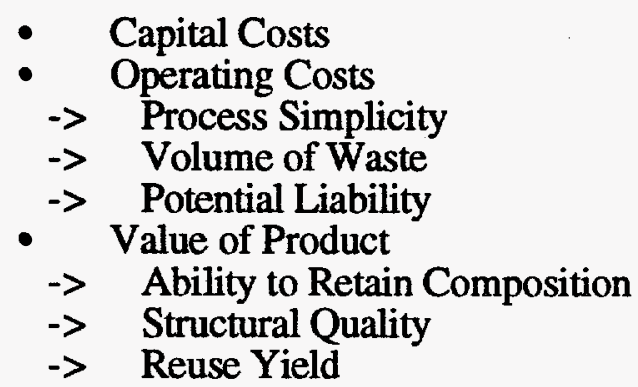

The capital costs associated with Surface Decontamination are low because it requires only a small amount of relatively simple equipment. These costs are further reduced because the process may be performed without extensive dismantling of structures and assemblies. Size Reduction, Packaging, and Burial also involves relatively inexpensive equipment - cutting, packaging, and cataloging systems. Of the melting processes, the lowest capital costs are associated with Air Induction Melting, and the greatest capital cost is incurred with either Plasma Arc Centrifugal Treatment or the combination of Vacuum Induction Melting followed by Electroslag Remelting. In the case of the former, the high costs are due to the complexity of the equipment. With $V I M+E S R$, the costs are due primarily to the vacuum system associated with VIM and because two processes are involved. To some degree, the capital costs associated with the furnaces, power supplies, and vacuum system in Plasma Arc Centrifugal Treatment, VIM or VIM + ESR are offset by the reduced costs associated with ES\&H concerns, such as the capture and handling of dust, smoke, or process effluents.

When the technologies are compared on the basis of operating costs, Plasma Arc Centrifugal Treatment is again the most costly because it requires large, complex equipment, which is expensive to operate and maintain, particularly once contaminated. However, Plasma treatment decreases the volume of waste by consolidation and creates only a small secondary waste stream. Further, the potential liability is low because the process is completely enclosed, minimizing personnel and environmental exposure. Utilization of Surface Decontamination is complex due to the uncertainty and constant need for verification of the degree of decontamination achieved. In addition, the volume of waste is increased because the process doesn't involve consolidation and creates a contaminated liquid waste stream. This added volume of contamination increases direct and indirect costs and creates an additional liability. Size Reduction, Packaging, and Burial is expensive primarily because of the degree of manual labor involved. The volume of waste produced is essentially equal to the volume of scrap metal with the addition of packing containers, but the liability and costs associated with personnel protection, and the fact that the material isn't decontaminated, are high. Vacuum Induction Melting, followed by Electroslag Remelting is essentially a self-contained recycle process, so the volume of waste is very low. As a two stage process, however, it is moderately complex and involves higher costs that VIM alone. Also, because radioactive material is handled between stages, and the ESR step is not completely contained, personnel and environmental exposure liability contribute to the operating costs. Arc Melting and Air Induction Melting are simple, widely used processes for the recycle of non-radioactive scrap metal. When used for decontamination, the volume of material is decreased via consolidation, but some waste is produced in the 
form of slag and refractory. These processes are inexpensive to operate, but incur added cost and liability associated with the production and handling requirements for toxic process dust. Vacuum Induction Melting is also a simple, widely used process, and provides the lowest operating costs. VIM completely consolidates the input material and produces a very small volume of waste in the form of spent refractory. VIM is fully enclosed, further limiting operating costs and liabilities and facilitating easy handling of volatile contaminants.

When the technologies are compared on the basis of the value of the product produced, Surface Decontamination and Size Reduction, Packaging, and Burial are poorly rated because they do not produce a reusable product. Plasma Arc Centrifugal Treatment, Electric Arc Melting, and Air Induction Melting produce a metal product which is neither fully decontaminated nor suitable for high technology applications due to poor structural and compositional control. The reuse yield of these processes is related to the amount of low technology product, such as reactor shielding, for which there is a need. Vacuum Induction Melting allows the retention, or modification, of the input material composition. Ingots are relatively inclusion free, but subject to extensive shrinkage porosity, making the material yield poor with respect to direct fabrication. The yield and decontamination is increased dramatically when Vacuum Induction Melting is followed by Electroslag Remelting. This process affords optimum compositional and structural control, combined with the most effective decontamination. Because initial composition is retained and structural quality is excellent, the yield of this process combination approaches 100 percent, and the output product is suitable for direct fabrication. 


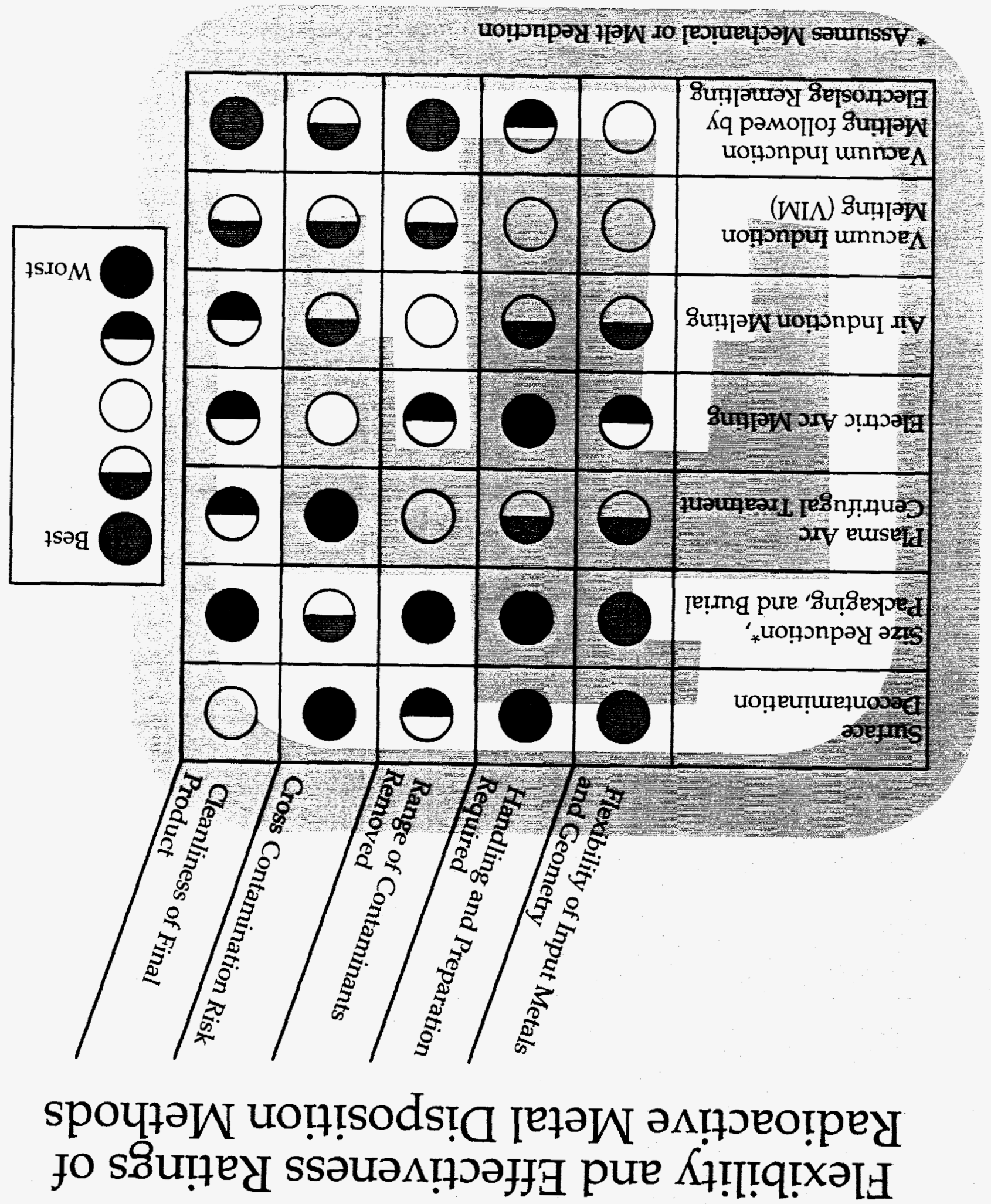




\section{Flexibility and Effectiveness Ratings of Radioactive Metal Disposition Methods}

The table depicted on the previous page compares the flexibility and effectiveness of the candidate processes with respect to five categories:

- $\quad$ Flexibility of Input Metals and Geometries

- Handling and Preparation Required

- $\quad$ Range of Contaminants Removed

- Risk of Cross-Contamination

- Cleanliness of Final Product

Flexibility of Input Materials refers to the ability of a process to accept different alloys and geometries. Generally, Surface Decontamination and Size Reduction, Packaging and Burial can immediately accept virtually any input stream because their goal is not the production of a specified output product. Plasma Arc Centrifugal Treatment and Air Induction Melting can accept a very wide range of materials, but some amount of size reduction and sorting is required to maintain a stable melt process and produce the desired output chemistry. Vacuum Induction Melting, singly or in conjunction with ESR, requires that scrap be cut into small pieces to avoid bridging in the furnace and process shutdown. Also, because a goal of these processes is the production of high-quality output material, the input stock is carefully sorted with respect to composition and impurity level. These concerns becomes more acute in the case of Electric Arc Melting because of the larger furnace size and the need for very finely divided scrap to avoid electrode damage.

In terms of Handling and Preparation Required, the Plasma Arc Centrifugal Treatment and Air Induction Melting processes are the best choices. In these processes, minimal size reduction and sorting are required, and the outputs are well consolidated metal and furnace refractory material, both easily handled. The worst processes with respect to handling and preparation are Surface Decontamination and Size Reduction, Packaging and Burial, where extensive handling and contact are required throughout.

Comparing the technologies with respect to their ability to remove a range of contaminants from the feed metal, Size Reduction, Packaging and Burial makes no attempt at contaminant removal. Surface Decontamination is the least efficient because it is unable to remove tenacious corrosion products, and cannot clean cracks, fine features, or complex geometries. Further, Surface Decontamination does not address bulk contamination. Plasma Arc Centrifugal Treatment and Electric Arc Melting, because they involve high temperatures, are somewhat effective at the removal of volatile radionuclides. These processes also offer some potential to address easily reacted radionuclides if a slag is used. In these processes however, a slag is typically not used because it often results in the entrapment of (radioactive) slag inclusions in the final product. Air Induction Melting can be effective at removing easily reacted elements, but does not address volatile elements. Conversely, Vacuum Induction Melting effectively removes only the volatile radionuclides. When Vacuum Induction Melting is followed by Electroslag Remelting, thermal and thermochemical processes are active, permitting both volatile and easily reacted contaminants to be effectively removed. Although none of the processes are currently capable of removing fission products, VIM + ESR and Plasma may offer the greatest potential because of their ability to access electrochemical and ionic interaction mechanisms.

The risk of cross contamination refers to the possibility that metallic scrap originally contaminated with one set of contaminants could become contaminated with others during 
the process. This risk is high for Surface Decontamination, especially if the decontaminant is recycled in an attempt to minimize secondary waste. Plasma Arc Centrifugal Treatment also carries a high risk due to the fact that a molten heel of metal is left in the furnace between heats. Electric Arc Melting may result in cross contamination because of a molten heel. Another possibility for cross-contamination in both Plasma and Electric Arc Melting arises from contamination of, and future contract with, the refractory used to line the furnace. A refractory furnace lining, hence the possibility of cross contamination, also exists with Air Induction Melting, Vacuum Induction Melting, and Vacuum Induction Melting followed by Electroslag Remelting if the refractory is used for multiple heats of metal. With Size Reduction, Packaging and Burial, the risk is primarily involved with the sorting and packing processes.

The primary goal of any decontamination process is to maximize the cleanliness of the final product. The process of Size Reduction, Packaging and Burial does not attempt to remove contaminants. Of the processes which attempt decontamination, Surface Decontamination is the least effective. Of the melting processes, Plasma Arc Centrifugal Treatment, and Electric Arc Melting are moderately effective at removing volatile contaminants, but not so much so as Vacuum Induction Melting, which operates in a high vacuum environment. Similarly, Air Induction Melting can remove easily reacted elements, but affords limited slag/metal interaction and is prone to the entrapment of slag inclusions. Electroslag Remelting on the other hand, maximizes slag/metal interaction and actually removes, rather than causes, inclusions. By far, the most effective of the decontamination method is a two-step process consisting of Vacuum Induction Melting followed by Electroslag Remelting. 


\section{Decontamination Mechanism Ratings of Radioactive Metal Disposition Methods}

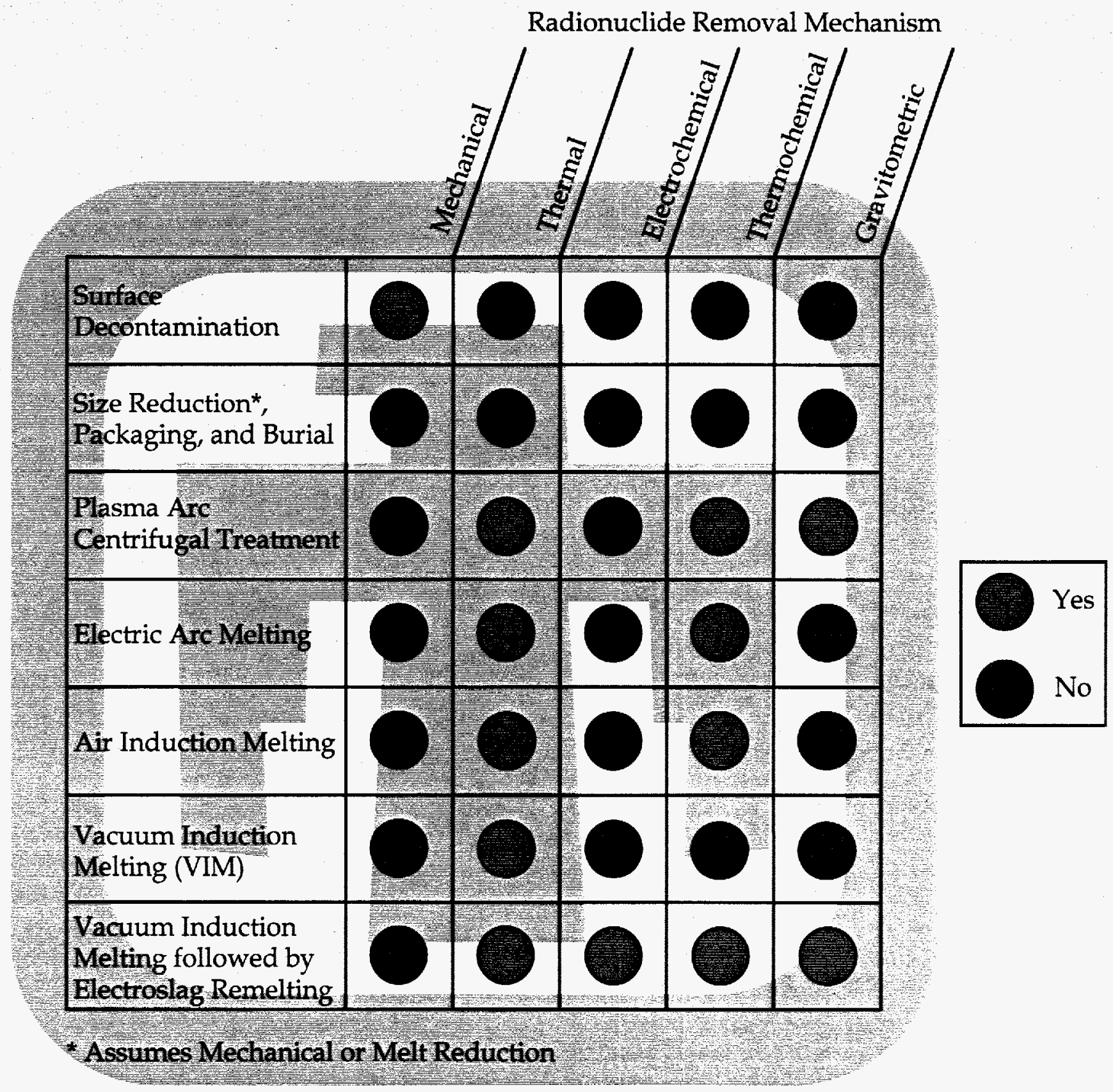




\section{Decontamination Mechanism Ratings of Radioactive Metal Disposition Methods}

The table depicted on the previous page is provided in order to compare the decontamination methods associated with several radioactive metal disposition methods. This table compares decontamination mechanisms found in the evaluated processes. For this purpose of this comparison, five decontamination mechanisms have been identified. These decontamination mechanisms are:

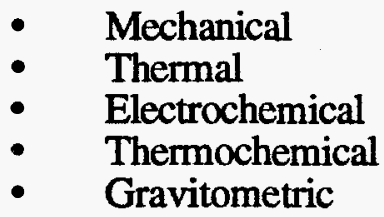

In comparing process efficiencies, it is useful to consider the decontamination mechanisms employed by each process. Surface Decontamination is usually a mechanical means of removing radioactivity that is concentrated on the surfaces of structures, although decontamination techniques employing chemical attack and anodic dissolution have been tested. The process of Size Reduction, Packaging and Burial does not attempt to remove contaminants. Plasma Arc Centrifugal Treatment employs thermal removal of volatile radionuclides, thermochemical transfer of species to a slag, and gravitimetric separation of heavy inclusions. Electric Arc Melting, and Air Induction Melting thermally remove volatile radionuclides and thermochemically transfer others to a slag phase. Vacuum Induction Melting is only effective at thermal removal of volatile radionuclides. Vacuum Induction Melting followed by Electroslag Remelting allows other decontamination mechanisms to come into play. During Electroslag Remelting radionuclides may be removed by thermochemical reactions with components in the slag. Due to the passage of current through the slag, electrochemical transfer may also take place. Nonmetallic inclusions present in the feed material remain in the slag as they are less dense than the metal, a gravitometric phenomena. 


\section{Experience Ratings of Radioactive Metal Disposition Methods}

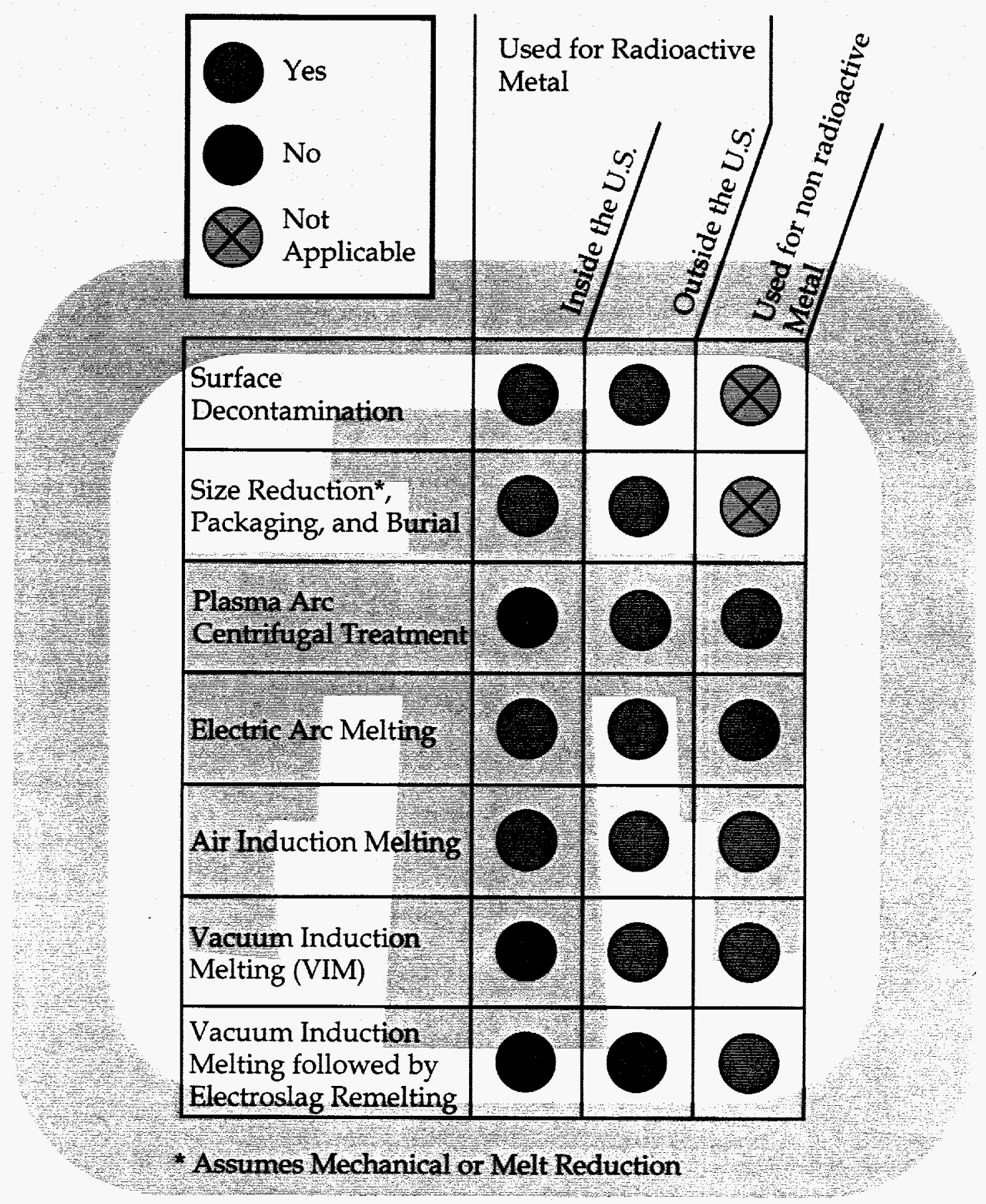




\section{Experience Ratings of Radioactive Metal Disposition Methods}

The table depicted on the previous page is provided in order to compare several radioactive metal disposition methods on the basis of process experience and use. An available process experience base provides an opportunity for significantly reduced learning curves and associated reduced costs. For this table, foreign and domestic utilization of the processes for radioactive waste are compared. In addition, commercial utilization of the process is also evaluated.

In order to aid in the selection of processes with the greatest probability of near term success, it is important to consider the extent to which each process has been used, both as a decontamination strategy and as a generic industrial process. Surface Decontamination has been employed both in the US and abroad, as has Size Reduction, Packaging and Buriall. Plasma Arc Centrifugal Treatment has been used in the US for non radioactive material (this process is an excellent strategy for the disposal of biohazards) and outside the US for radioactive scrap decontamination. In the 1950s and 1960s Electric Arc Melting was used for the dilution of radioactive scrap and some of the resultant material was released to the open market (see Appendix 2). Electric Arc Melting and Air Induction Melting are widely used for the recycle of non radioactive scrap and Air Induction Melting is being used around the world for radioactive scrap metal decontamination, probably because of the low capital costs required and the simplicity of the operation. Vacuum Induction Melting is used as a production step in the manufacture of specialty alloys. This process is being used in Japan for the melt consolidation of non-radioactive scrap metal. Vacuum Induction Melting followed by Electroslag Remelting is a strategy employed by the makers of specialty metals and alloys to insure the production of materials with optimum structure and properties. This process lends itself to the decontamination of high performance alloys because it allows their original value to be maintained while providing the maximum potential for decontamination. 


\section{Section IV - Process Selection}

Whenever radioactive materials are to be processed, the exposure risk to associated personnel must bear considerable evaluation. However, the processes under evaluation are either already in use or, by their very nature, provide enhanced containment and reduced risk. It is of interest to note that those processes with the greatest degree of present utilization are typically those with the greatest risk. As such, it has been concluded that none of the processes under review constitute an unacceptable risk. When viewed from a disposal standpoint, the Plasma Centrifugal Treatment Process represents the lowest risk to personnel and the environment, however it does not effectively recycle the valuable metal resource. In contrast, a Vacuum Induction melt followed by an Electroslag Remelt is nearly as effective while maintaining the value of the input feed.

Often the most significant cost associated with the final disposition of radioactive material is that associated with storage or burial. For this reason, technologies which reduce the volume of material in need of disposal represent significant potential cost savings. Of the methods listed, those which employ a melting process achieve the greatest degree of densification and therefore as a pre-burial step can significantly reduce storage or disposal costs. When viewed solely as a process for the consolidation and containment of radioactive scrap metal, the Plasma Centrifugal Treatment Process provides the greatest flexibility of feed and hence ease of processing. However if volumetric reduction is the primary goal, then a decontamination and recycling process provides a substantial reduction in waste.

The advantages associated with recycling valuable materials, as opposed to throwing them away, are self evident. Given this assumption, the ability to process contaminated scrap in such a fashion as to maintain or enhance its value is significant. In conjunction with the maintenance of the metallurgical value, the degree of decontamination must also factor heavily when the ultimate disposition of the processed material is considered. When viewed from these metallurgical standards, a vacuum induction melt followed by an electroslag remelt provides the greatest decontamination while producing a material with characteristics that meet or exceed those available from the mill.

The primary consideration of this review is the recovery of the valuable resource represented by radioactively contaminated scrap metals. As such, the process combination of VIM and ESR provides the most effective combination of value retention and decontamination of the metal, and stabilization of the radioactive contaminants. The resultant ESR ingot is suitable for direct rolling or forming, representing the required feed stock for the subsequent manufacture of controlled use products and waste storage containers. 


\section{Section V - Research and Development Proposal}

The proposed research is a focused two-year development program ending with a full scale industrial demonstration of the technology. The program will consist of two concurrent elements. The first will be the development and optimization of a process aimed at a specific source/repository of radioactive scrap metal of consistent composition and contamination. A target will be selected to facilitate the demonstration of a near-term application with maximum immediate payoff. Parallel to the process development and optimization for a particular input stream, the understanding and technology base necessary to support the process, and its future adaptation to other input streams, will be built. These activities will include process/parameter modeling and a characterization and study of the decontamination mechanisms involved in the target application. Six specific research and development tasks to be included in the overall program are as follows:

\section{V.1 Thermodynamic Modeling of Radionuclides in Slags}

A fundamental understanding and thermodynamic description of the driving forces which govern decontamination reactions are required to model the behavior and partitioning of surrogates, radionuclides, and alloying elements between a metal and a slag. Preliminary thermodynamic models, developed in a recent pilot study, will be further refined and validated by a study of elemental partitioning in electroslag remelting. When fully developed, this model will support the selection of optimum slags to be used in the decontamination process. The selection of slags and any metal and combination of contaminants will allow computational studies of process and parameter sensitivity to be conducted. This model will be of great value because it will both ensure that the target application is optimized and eliminate much of the developmental work necessary to apply the technology to other input streams. (Months 1-24)

\section{V.2 Solidification Studies of Slags}

To support the development and bench marking of the thermodynamic slag model, a series of controlled solidification studies will be conducted on a range of slag compositions. The goal of these studies is to develop, and incorporate in the model, a thorough understanding of the phase stability and solidification behavior of slags. Several slag compositions will be characterized, both to develop a series of slags for further study, and to validate model predictions by displaying a specific behavior. (Months 3-12)

\section{V.3 Electroslag Melting Studies with (surrogate) Contaminated Feed Stock}

A series of experimental melts will be conducted using feed stock contaminated with surrogate radionuclides and experimental slags which have been selected as a result of the modeling and solidification studies. Surrogate materials, and their method of application, will be selected to physically and thermodynamically emulate the contaminants present in the selected target input steam. Tests will be conducted to evaluate the slag behavior and performance, and to characterize the interaction of the slag properties with the process mechanisms and controls. Chemical analysis of the metal and the slag will be performed and the results will be used to benchmark the thermodynamic and process models. The dual effects of slag chemistry and solidification mechanisms on the partitioning of radionuclides between the slag skin and the slag cap will also be studied, via microprobe analysis of slag skin and cap material to characterize the solidification paths. In 
addition to decontamination efficiency, a key property to be optimized in slag behavior is control of the elemental partitioning within the slag system. As such, it is intended that slags which both entrap the radionuclides and cause them to partition to the slag cap shall be developed. An additional goal of the optimization is to design slags which bind the radionuclides in a chemically stable form. (Months 6-18)

\section{V.4 Pilot Scale Work Involving Vacuum Induction Melting Followed by Electroslag Remelting.}

The overall decontamination process which appears to offer the best performance combines Vacuum Induction Melting (VIM) with ESR. The VIM process must be conducted in a manner which maximizes removal of the volatile contaminants and provides an optimum electrode for ESR. This task combines the two processes and begins the optimization of both the VIM step, and the two processes in series. Factors to be investigated include residence time and temperature in the VIM, and further optimization of the ESR process using the VIM electrode. ESR factors for further optimizization include slag chemistry, amount and compositional variation of slag, melt rate, and control strategy. The goal being production of ingots with optimum surface quality and internal structure. This task leads directly to the full scale industrial demonstration to be performed with radioactive material. These melts will be conducted in conjunction with our industrial partner, and will provide information regarding optimum operating parameters to use in the full-scale demonstration. (Months 12-24)

\section{V.5 Full Scale Industrial Demonstration of Radioactive Metal Decontamination}

This full scale demonstration will be performed by an industrial partner (already identified) in their facility. The input material will be from the source initially selected and used as the focus of this study. The metal will be melted in a vacuum induction furnace under the conditions arrived at in step three, above. Volatile radionuclides will be captured by a filtering system. After melting, the metal will be cast into an electrode for the electroslag remelting process. The metal will then be melted by ESR, using a slag chemistry selected during steps 1 and 2 above. The resulting ingot will be analyzed for radioactivity to validate the process and models. (Months 18-24)

\section{V.6 Existing Assets at Sandia}

The Liquid Metal Processing Laboratory (LMPL) at Sandia National Labs in Albuquerque is a unique resource and represents the state of the art in melting technology within the United States. The execution of this project will be conducted at the Liquid Metal Processing Lab and will utilize the following LMPL resources:

- The Liquid Metals Processing Laboratory has one open air induction furnace, two vacuum induction furnaces as well as a nearly full scale Electroslag Remelting Furnace.

- Control systems allow optimum decontamination efficiency by controlling the amount of time reactions have to take place. Personnel at the Sandia's Liquid Metal Processing Laboratory have several patents for control systems, one of which is in use in a large industrial facility. 
- Sandia's Liquid Metal Processing Laboratory personnel have interacted for 6 years with an industrial consortium which uses Electroslag Remelting in the production of specialty alloys, the Special Metals Processing Consortium (SMPC). Interactions have included work on control systems and other research areas related to Electroslag Remelting.

- Sandia has an existing technical relationship and on-going programs with a private company interested in radioactive scrap metal melt decontamination.

\section{V.7 Support of Sandia's Core Competency}

Sandia is the DOE's preeminent facility and expertise in the area of liquid metal processing. This capability is a key component in Sandia's DP mission, supplying custom materials for production and R\&D programs, such as controlled composition alloys for weldability studies (gas bottles) or molybdenum-vanadium alloys for cermet production (neutron generators), and fireset or radar housings for stockpile maintenance and upgrade efforts. Additionally, the liquid metal processing area, through industrial consortia such as FASTCAST and the Specialty Metals Processing Consortium, is leveraging its research program, while maintaining and enhancing a strong domestic vendor base which supports Sandia's production mission. A third area of support for the DP mission is through direct production support for melting and casting production throughout the DOE complex, particularly significant now that the complex is being re-configured. Electroslag remelting and vacuum induction melting are key processes in the production of custom and specialty metals. In addition to directly impacting DOE's EM effort, the performance of this research at Sandia provides leveraging for both this program and Sandia's core capabilities in the areas of liquid metal processing, modeling, and process control. 


\section{Appendix 1 \\ Decontamination of Stainless Steel by Electroslag Remelting: A Feasibility Study}

\section{A1.0 Overview}

This research, performed at the Liquid Metals Processing Laboratory at Sandia National Laboratories, was directed at the partitioning of surrogate radionuclides (rare earth elements) between 304L stainless steel and slag in ESR. Melting experiments were performed using slags with various ratios of $\mathrm{CaF}_{2} / \mathrm{CaO} / \mathrm{Al}_{2} \mathrm{O}_{3}$. Slag chemistry was shown to influence the partitioning of surrogates between the slag skin, which forms along the water cooled copper crucible wall and the slag cap, which, at the end of melting, is a solid piece of slag on top of the ingot produced. Ideally, the radionuclides would be partitioned to the slag cap, facilitating contaminant containment and disposal. Thermochemical modeling was undertaken to explain trends observed in the partitioning of rare earth elements.

\section{A1.1 Melting Experiments}

Stainless steel (304L) electrodes measuring 2.5 " in diameter were coated with various blends of rare earth element oxides to simulate piping from nuclear power plants. These electrodes were melted into a 3.75 inch diameter round mold using thirteen different slags. This group of slags represented a factor space on the ternary $\mathrm{CaF}_{2} / \mathrm{CaO} / \mathrm{Al}_{2} \mathrm{O}_{3}$ slag phase diagram. Melting was conducted at a constant melt rate and utilizing a proprietary Sandia developed control strategy. Slags used in this research were produced at the Liquid Metal Processing Laboratory by pre-fusion of the components in a small air induction furnace. These slags were then crushed and blended in preparation for use in the ESR. The goal of this research was to recommend a set of conditions suitable for the safe and effective treatment of radioactive scrap metal by ESR. After melting, each ingot was examined to evaluate its surface quality. Surface quality is of concern in an actual remelt operation because ideally, very little surface conditioning should be required before ingots are formed to shape. Chemistry sampling was conducted in order to evaluate the amount of rare earth elements present in the steel, as well as to determine changes in the base chemistry. Chemical analysis was also performed on each slag cap and slag skin. During each melt, changes in current, voltage, power, and impedance were electronically recorded.

\section{A1.2 Thermochemical Modeling}

In order to determine the potential of each slag for the retention of elements or alternatively, encouraging the segregation of such elements to the ingot, work on a thermochemical model for the slags was initiated. This model is intended to predict the chemical behavior of a given slag in contact with a liquid metal. The model which has shown the greatest potential to date is a modified Tempkin model. While classical models assume slags to be ionic, a modified version uses electrically equivalent ion fractions to ensure that charge balance rules are obeyed. Since this model provides the prediction of theoretical activities of slag components, partition coefficients may be utilized to predict the degree to which a given element will be captured in the slag and how much will be retained in the ingot. This modeling effort is important because the melting study was performed with rare earth elements selected on the basis of their thermochemical similarity to 
transuranic elements. Thermodynamic modeling allows the prediction of what will happen when melting is performed with actual radionuclides.

\section{A1.3 Results}

Melting results demonstrated that rare earth elements applied to the ingots were completely transferred, thereby achieving $100 \%$ decontamination of surrogates. This result was achieved regardless of slag chemistry. Therefore, if a process were to be initiated with the goal of decontaminating radioactive steel scrap, its effectiveness would not be compromised by the time dependent changes in the slag chemistry which may occur during the course of a melt. However, in cases where the chosen slag resulted in a poor ingot surface, there are indications that slag inclusions entrapped at the surface would cause ingot radioactivity to be higher than for ingots with a good surface. As a result, if optimum decontamination levels are to be insured, ingots should have excellent surface quality and radionuclides should be preferentially present in the slag cap.

Interestingly, this study showed that, by changing the slag chemistry, the rare earth elements used to simulate radionuclides could be partitioned to either the slag skin or to the slag cap. This result may be explained by examining the solidification mechanism for each slag in conjunction with the rare earth phases predicted by the thermochemical model. When a molten slag comes in contact with a cold copper jacket, the component of the slag with the highest melting point may be assumed to solidify first. Depending on the chemistry of the slag, the rare earths may be present as low melting point fluorides or higher melting point oxides or aluminates. The chemical form taken by the rare earth elements may be predicted by use of the thermochemical slag model. If the highest melting point component in the slag is a rare earth compound, then the rare earth element will be concentrated in the slag skin. Conversely, if the rare earth is present in a form with a lower melting point than the oxide-fluoride mix predicted by the phase diagram, the rare earth will tend to be present in the slag cap. Thermochemical modeling may be used for the prediction of the amounts of given radionuclides which will be captured in the slag and their chemical forms. Further work is necessary to evaluate the accuracy of this model and to modify it accordingly. Completion of an accurate thermodynamic model will allow the prediction of the chemical form of radionuclides in the slag and will facilitate predictions of their long term chemical stability. 


\section{Appendix 2 \\ Melting as a Decontamination Process}

\section{A2.1 History of Radioactive Scrap Metal Melting}

Interest in decontamination of steels began in the 1950s when the accumulation of uranium contaminated scrap at some locations increased to an onerous level. The first production scale steel decontamination project described in the literature involved 6000 tons of low level contaminated metal waste and was undertaken by the National Lead Co. of Ohio ${ }^{1}$. Their efforts focused on monitoring the exposures of foundry personnel that resulted from processing this waste. A commercial steel mill used an electric arc furnace to melt the scrap which consisted of discarded uranium extraction equipment and baled drums which had been used for shipping uranium concentrate.. The ingots averaged less than 3 ppm U and the slag contained $2.12 \% \mathrm{U}$. The slag weight constituted $8.5 \%$ of the weight of the steel melted. By calculation, the average original uranium content of the scrap was $2000 \mathrm{ppm}$. The level of contained uranium in the ingots was below regulatory concern and they were sold on the commercial scrap market while the slag was shipped to Oak Ridge for disposal. In 1958, the same process was applied to 350 tons of radium bearing scrap. After melting, the ingots averaged $9.0 \times 10^{-13} \mathrm{~g} \mathrm{Ra} / \mathrm{g}$ steel and the slag averaged $1.47 \times 10^{-}$ ${ }^{9} \mathrm{~g} \mathrm{Ra} / \mathrm{g}$ steel.

In 1956, Atomic Energy Commission policy permitted free disposal of uraniumcontaminated ferrous scrap when certain radioactivity restrictions were met. Kelvin and Harris $^{3}$ did a study with the purpose of demonstrating that, within certain limits, uranium contaminated iron and steel could be released into normal trade channels. Uranium contaminated scrap metals were obtained from various AEC uranium production sites, analyzed for alpha activity and uranium content, and were then induction remelted in a manner similar to that used in industrially treating scrap. Stainless-steel, copper, nickel, and nickel-steel ingots were made by melting 20-30 lbs of scrap in a magnesia or graphite crucible and casting into molds. Dust samples were taken directly above the crucibles in order to evaluate the health hazard of uranium carrying dust. After remelting, surface alphaactivity measurements were made on the individual ingots. The authors concluded that "airdust samples revealed that no hazard should exist from dust or fumes during such remelting operations" because, with "a single exception, all samples taken during the remelting processes indicated atmospheric uranium concentrations below $10 \mathrm{dpm} / \mathrm{m}^{3}$ (decays per minute) or less than $1 \%$ of the maximum permissible concentration". However, the one high sample showed a concentration of 80 alpha $\mathrm{dpm} / \mathrm{m}^{3}$. Nevertheless, the researchers concluded that "the remelting of large quantities could be safely accomplished." The research did show that uranium contaminated stainless steel, nickel, and copper was decontaminated down to about $1 \mathrm{ppm}$ by remelting, although the ingot surfaces showed higher concentrations. Other conclusions, surprising by today's standards included: "The

\footnotetext{
${ }^{1}$ Starkey, R.H., McKekvey, J.W., Held, B.J., Alpaugh, E.L., "Health Aspects of the Commercial Meltng of Uranium-Conaminated Ferrous Metal Scrap," American Industrial Hygiene Association Journal, Vol. 21, pp. 178-181, 1960.

${ }^{2}$ Starkey, R.H., Quigley, J.A., McKelvey, J.W., "Health Aspects of the Commercial Meltng of Radium-Conaminated Ferrous Metal Scrap," American Industrial Hygiene Association Journal, Vol. 22, pp. 489-493, 1961.

${ }^{3}$ Klevin, P.B. ; Harris, W.B. "Remelting May Permit Reclaiming Uraninum-Contaminated Metals" Nucleonics, April 1956. pp. 93-96.
} 
remelting of this type of material can be accomplished without hazard to personnel." Also "The contaminated slag contains significantly less uranium than a very low-grade ore, such as phosphate rock, and disposal should be permitted on normal slag dumps."

The Y-12 plant at Oak Ridge supervised the melting of a 20 year accumulation of low level contaminated metal waste in a 10 ton electric arc furnace. 27000 tons of scrap were melted requiring 2037 heats for the carbon steel scrap and 218 heats for the stainless steel scrap. The mild steel ingots averaged $0.4 \mathrm{ppm}$ with $94.3 \%$ of the heats containing 1 ppm or less of uranium while the stainless heats averaged $0.6 \mathrm{ppm}$ with $79.8 \%$ of the heats containing $1 \mathrm{ppm}$ or less. The slags for the carbon steel heats averaged $2630 \mathrm{ppm}$ uranium. This production scale work was reported by Mautz in 1975 in a handbook which provided up to date information on uranium decontamination of common metals by smelting.

\section{A2.2 Technology Development}

The problem of radioactive scrap metal decontamination and disposal is of concern throughout the industrialized world. Researchers in many countries have conducted work, individually and as cooperative research groups, to develop safe and effective methods for the melt densification and decontamination of radioactive scrap metal.

Bench scale melting tests for the removal of uranium and transuranics have been conducted by several researchers. At Argonne National Laboratory, Seitz, Gerding, and Steindler ${ }^{5}$ studied the decontamination of mild steel, stainless steel, and nickel contaminated with $400-1400 \mathrm{ppm}$ of plutonium oxide. Contaminated metals were melted in a resistance furnace in the presence of silicate slags of various compositions. Several crucible materials were tested to determine their ability to contain molten slag and steel without chemical attack or cracking. Magnesium oxide crucibles were attacked by a calcium silicate slag, while calcia stabilized zirconia crucibles were subject to cracking. The best crucible material tested was re-crystallized alumina. After melting, the major source of activity remaining within the ingots was found to be due to the incomplete separation of the silicate slag from the steel. Plutonium was found throughout the ingot in the form of small clusters which were thought to be precipitated as the metal cooled, as was suggested by their uniform spacing and size. In all experiments performed, the plutonium was strongly fractionated into the slag phase. The chemistry of various slags tested had some effect on plutonium extraction. Partition coefficients (plutonium in slag/plutonium in steel) of $7 \times 10^{6}$ were measured with borosilicate slag and $3 \times 10^{6}$ for calcium-magnesium-silicate slag. The researchers noted that some of the borosilicate slags were inhomogeneous with higher plutonium and chromium concentrations in regions of high alumina content.

Staged melting was found to improve decontamination efficiencies. Staged melting was done on one heat where portions of two previously melted ingots were remelted using a clean slag. This resulted in an even greater reduction in Pu content. The initial content of the charge was reported as about $0.1 \mathrm{ppm} \mathrm{Pu}$ while the ingot resulting from this melt averaged $0.002 \mathrm{ppm} \mathrm{Pu}$. This reduction was postulated to be the result of the removal of $\mathrm{Pu}$ containing inclusions. The possibility was considered that a similar result could have

\footnotetext{
${ }^{4}$ Mauutz, E.W., Briggs, G.G., Shaw, W.E., and Cavendish, J.H., "Uranium Decontamination of Common Metals by Smelting: A Review (Handbook)," NSA 3204, National Lead Company of Ohio, Cincinnati, Ohio, Feb., 1975a.

${ }^{5}$ Seitz, M.G., Gerding, T,J., Steindler, M.J., "Decontamination of Metals Containing Plutonium and Americium" ANL-78-13, UC-70, UC-10, Argonne National Laboratory, June 1979.
} 
been obtained by a longer holding time in the crucible to allow time for the oxide inclusions to coalesce and float into the slag. The inclusions still trapped in the first melt (which had a duration of one hour) had an additional hour to float to the surface in the second melt. Two other single melts held for two hours under a borosilicate slag yielded similarly low $\mathrm{Pu}$ contents, leading to a conclusion that longer holding times may be nearly as effective as staged melting.

In 1978, Copeland, Heestand, and Mateer ${ }^{6}$ of Oak Ridge National laboratory published a report in which they detailed both the theoretical thermodynamics and the practical engineering aspects of planned metal melt decontamination research. In fulfillment of these plans, researchers ${ }^{7,8}$ studied the effect of slag composition and other processing variables on the degree of decontamination achieved in the melt refining of metals contaminated with $\mathrm{UO}_{2}$. Samples were contaminated by addition of $\mathrm{UO}_{2}$ to the flux, which was added to the metal in a crucible. Melting was then performed at approximately $1600^{\circ} \mathrm{C}$ in an induction furnace and time was allowed for slag metal equilibration. After cooling, samples were taken of the metal and the slag. The degree of decontamination was not reported to be highly dependent upon slag composition although low efficiencies were associated with high silica slags. In general, highly fluid basic oxidizing slags were found to be more effective in decontamination of stainless steel.

A logical continuation of the melting work performed at Oak Ridge involved a potential disposal method for the resulting contaminated slags. The feasibility of sizereducing and disintegrating slags was studied. Solidified slags generated in melt refining were crushed and reduced in size to less than $3 \mathrm{~mm}$. The size reduced slags were mixed with cement and found to form stable grout mixtures. ${ }^{10}$

A six ingot scoping study was performed at Hanford ${ }^{11,12}$ using an induction furnace to make $5 \mathrm{lb}$ melts. The charge for each melt consisted of five uncontaminated stainless steel bars, two of which were then contaminated as follows: one bar was painted with a slurry containing $\mathrm{PuO}_{2}$ so that the bar contained 0.8 to $1.0 \mathrm{~g}$ of $\mathrm{Pu}$ (an addition to the total melt of 350 to $440 \mathrm{ppm}$ ) and another bar was dipped into an acidified solution of

${ }^{6}$ Copeland, G.L., Heestand, R.L., Mateer, R.S., "Volume Reduction of Low-Level Contaminated Metal Waste by Melting: Selection of Method and Conceptual Plan," ORNL/TM-6388, Oak Ridge National Laboratory, June, 1978.

${ }^{7}$ Heshmatpour, B., Copeland, G.L., "The Effects of Slag Composition and Process Variables on Decontamination of Metallic Wastes by Melt Refining," ORNL / TM-7501, UC-70, Oak Ridge National Laboratory, Jan., 1981a.

${ }^{8}$ Heshmatpour, B., Copeland, G.L., "Metallurgical Aspects of Waste Metal Decontamination by Melt Refining," Nuclear and Chemical Waste Management, Vol. 2, pp. 25-31, 1981.

${ }^{9}$ Heshmatpour, B., Copeland, G.L., Heestand, R.L., "Decontamination of Transuranic Waste by Melt Refining" ORNL/TM-7951, 1981; Nuclear and Chemical Waste Management, Vol. 4, pp.129-134, 1983.

${ }^{10}$ Heshmatpour, B., Copeland, G.L., Heestand, R.L. "Granulation of Slags and Metals After Melt Refining of Contaminated Metallic Wastes," Nuclear and Chemical Waste Management, Vol. 2, pp.33-37.

${ }^{11}$ Hobbick, C.W., Schatz, D.R., "Aden, G.D., "Distribution and Removal of Radionuclides in Molten Stainless Steel," RHO-CD-1444, June, 1981.

${ }^{12}$ Deichman, J.L., "Contaminated Metallic Melt Volume Reduction Testing," ORNL/NFW81/34, Oak Ridge National Laboratory, 1981. 
beta-gamma source from Hanford "tank waste" and was thus coated with ${ }^{60} \mathrm{Co},{ }^{137} \mathrm{Cs}$, and ${ }^{155} \mathrm{Eu}$. A flux resembling the borosilicate glass composition was used, but the high $\mathrm{SiO} 2$ content caused attack of the $\mathrm{MgO}$ crucibles. After melting, autoradiographs showed that the ingot contamination was concentrated on the surface of the ingots and in inclusions. Ingot analysis by wet chemistry showed levels of residual $\mathrm{Pu}$ in the 0.1 to $0.085 \mathrm{ppm}$ range, while an approximate $98 \%$ reduction of beta, gamma, and actinide levels was achieved.

Stainless steel scrap melting work at the Idaho National Engineering Laboratory ${ }^{13}$ was concerned primarily with reducing the volume of the scrap to conserve dwindling waste storage capacity. The Waste Experimental Reduction Facility (WERF) was established to process a variety of low-level beta/gamma contaminated waste. A $750 \mathrm{~kW}$ induction furnace was used to demonstrate that melting the scrap and casting in into 680 $\mathrm{kg}$ ingots was a safe and effective method for achieving at least a 10 fold reduction in volume while converting the scrap into a readily packagable form and stabilizing any radioisotopes remaining in the ingots. The contaminated feed stock was generated by various INEL facilities and consisted mostly of salvaged reactor and test support components that were surface contaminated only. The major contaminants were ${ }^{60} \mathrm{Co}$, ${ }^{90} \mathrm{Sr}$, and ${ }^{137} \mathrm{Cs}$. Because the radioactivity level of the ingots produced had been too low to formulate a basis for the prediction of the dispersion of isotopes resulting from melting, three spiked melts were made using sub-sized $(200-300 \mathrm{~kg}$ ) heats. Known quantities of ${ }^{60} \mathrm{Co},{ }^{85} \mathrm{Sr}$, and ${ }^{137} \mathrm{Cs}$ were added to uncontaminated stainless steel. ${ }^{85} \mathrm{Sr}$ was used instead of ${ }^{90} \mathrm{Sr}$ because ${ }^{85} \mathrm{Sr}$ is a gamma emitter and therefore easier to detect in minute quantities. After melting, $91-100 \%$ of the $\mathrm{Co}, 0-15 \%$ of the $\mathrm{Cs}$ and $0-4 \%$ of the $\mathrm{Sr}$ remained in the ingots. Most of the Sr was collected in the high silica slag used, while most of the Cs went into the baghouse. Distributions in the slag were difficult to measure because slag remained attached to the ingot and the dipping tools, while some reacted with the furnace refractory and remained in the furnace.

In the mid 1980s, researchers in Japan published the results of several studies undertaken to study the melt decontamination of radioactive metals. Researchers at Kobe Steel, Ltd. and Power Reactor and Nuclear Fuel Development Corporation ${ }^{1415}$ investigated the use of electroslag remelting to decontaminate plutonium contaminated waste. This melting method was expected to have advantages as a process for treating radioactive metallic waste. Because melting and solidification take place in the same water cooled copper mold, no refractories are necessary, equipment needs are simplified, and volume reduction and radionuclide immobilization are accomplished simultaneously.

${ }^{13}$ Reimann, G.A. "Technical Assement of Processes to enable Recycling of Low-Level Contaminated Metal Waste," EGG-WTD-10056, Idaho National Engineering Laboratory, Jan., 1992.

${ }^{14}$ Kitagawa, K., Nagura, K., Noura, T., "Treatment of Radioactive Metallic Waste by the Electro-slag Melting Method,"Kobe Steel Engineering Reports, Vol. 33, No. 1, Jan. 1983.

${ }^{15}$ Ochiai, A., Kitagawa, K., Sawada, Y., Isuhara, S., Ohtsuka, K., "Treatment of PlutoniumContaminated Metallic Waste by the Electro-slag Melting Method," IAEA-SM-261/20; EDB-84-020441, Japan: Kobe Steel, June, 1982. 
Radioactive particles on the surface of the metallic waste can be transferred to the melted slag. Test work was performed using $\mathrm{HfO}_{2}$ as a surrogate for $\mathrm{PuO}_{2}$, because of the similarity of properties. A $10 \mathrm{~kg}$ pilot scale furnace was used to become familiar with ESR operations, after which a $100 \mathrm{~kg}$ furnace was constructed and used for simulated decontamination tests. The furnace featured a rectangular copper mold and two $50 \mathrm{~mm}$ tungsten bars which served as non-consumable electrodes. The slag used had a composition of $47 \% \mathrm{CaO}, 48 \% \mathrm{Al}_{2} \mathrm{O}_{3}$, and $5 \% \mathrm{~B}_{2} \mathrm{O}_{3}$ and was selected on the basis of mechanical strength to insure stability in long term storage. The furnace was fed with pieces of surrogate treated metal ( $67 \mathrm{ppm} \mathrm{Hf}$ ) by use of a bucket mechanism which moved up and down, receiving pieces of metal in the upper position then descending over the melted slag and depositing the metal into the melted slag. The time required to melt $100 \mathrm{~kg}$ of metal pieces at $140 \mathrm{kVA}$ was about 100 minutes. Upon evaluation of both ingot and slag for hafnium content, it was found that the solidified slag contained $298 \mathrm{ppm} \mathrm{Hf}$ and the ingot contained $2.53 \mathrm{ppm} \mathrm{Hf}$, yielding a decontamination factor of about 25 .

Electroslag refining was also the subject of a study by Uda, Ozawa, and $\mathrm{Iba}^{16}$ who investigated the potential of this method for melting of uranium contaminated metal cylinders. Electroslag refining was selected because many metallic wastes in the forms of rods, cylinders, and tubes can be melted without cutting them into pieces. The aim of this study was to establish ESR melting conditions for metal cylinders in which the cross section ratio of electrode to mold was less than the usual industrial ratio of 0.3 to 0.6 while comparing the decontamination efficiency of ESR with that for a resistance furnace. The ESR test equipment consisted of a $60 \mathrm{~mm}$ water cooled copper mold, an AC power supply, an electrode position controller and an off gas line and filter for removal of fume from the enclosed melting chamber. During each test, a uranium contaminated consumable electrode was melted through a molten slag pool by application of electric power which resistively heated the slag. The voltage for these melts was 40 to 50 volts while the current was 300 to $1000 \mathrm{amps}$. Cylinders of iron and aluminum were prepared for melting by application of a uranium containing solution to their surfaces so that the resultant uranium concentration was $500 \mathrm{ppm}$. The flux composition used for the experiments was $40 \% \mathrm{SiO} 2-30 \% \mathrm{CaO}-20 \% \mathrm{Al} 2 \mathrm{O} 3-10 \% \mathrm{CaF} 2$ for the iron, and $14 \% \mathrm{LiF}-76 \% \mathrm{KCl}-$ $10 \% \mathrm{BaCl}$ for the aluminum. After melt refining was completed, the uranium concentration in the ingot was determined and the energy efficiency was calculated. The energy efficiency is defined as the heat used to melt the metal divided by the electric power supplied. The heat used to melt metal can be estimated by multiplying the heat capacity and the heat of fusion of the metal by the melt rate. Iron and aluminum cylinders of various wall thicknesses (fill ratios) with a uranium concentration of $500 \mathrm{ppm}$ were melted. It was determined that the decontamination achieved was independent of melt rate. The decontamination effect achieved with ESR was better than that obtained with a resistance furnace. The final ingot concentrations of the iron were 0.01 to $0.015 \mathrm{ppm}$ which were less than the as received specimen before contamination, although ingot levels for the aluminum were 3 to $3.5 \mathrm{ppm}$ which were a few times higher than in the as received condition.

${ }^{16}$ Uda, T., Ozawa, Y., Iba, H., "Melting of Uranium-Contaminated Metal Cylinders by Electroslag Refining," Nuclear Technology, Vol.79, pp. 328-337, 1987. 
Uda, Iba, and Tsuchiya ${ }^{17}$ investigated the effect of slag chemistry on the melt refining of mild steel. In a related study, $\mathrm{Abe}, \mathrm{Uda}$, and $\mathrm{Iba}^{18}$ melted samples of uranium contaminated mild steel, 304 stainless steel, and copper under various $\mathrm{SiO}_{2}-\mathrm{CaO}-\mathrm{Al}_{2} \mathrm{O}_{3}$ slags. Other variables included in these studies were contamination levels and melting times and temperatures. The aim of this research was to establish an optimized decontamination strategy for various metal types. Rods of the metals to be melted were contaminated by dipping in a uranyl nitrate solution of known concentration and were subsequently heated to decompose the uranyl nitrate. Uranyl nitrate decomposes to $\mathrm{UO}_{3}$ between 200 and $300^{\circ} \mathrm{C}$ and $\mathrm{UO}_{3}$ loses oxygen to give $\mathrm{U}_{3} \mathrm{O}_{8}$ or $\mathrm{UO}_{2}$ above $800^{\circ} \mathrm{C}$. Samples were then melted in an enclosed furnace under an argon atmosphere. The results of various tests revealed that slag chemistry was an important factor in decontamination efficiency. The ionic character of a slag may be represented by its basicity, which is defined as the moles of basic oxide $(\mathrm{CaO})$ divided by the total moles of acidic oxide $\left(\mathrm{SiO}_{2}\right.$ $+\mathrm{Al}_{2} \mathrm{O}_{3}$ ). The most effective slag basicity was around 1.5. Fluxes containing $\mathrm{CaF}_{2}$ were more effective, possibly because as fluorides break the bonds of the silicate network present in $\mathrm{SiO}_{2}$ containing slags, ${ }^{19}$ additional $\mathrm{SiO}_{4}{ }^{4-}$ anions are produced which could combine with uranyl cations at the slag metal interface, causing uranium capture in the slag. Slags containing $\mathrm{NiO}$ also proved to be effective because the oxide breaks down to yield free oxygen ions which also break down the silicate network causing the formation of acid slag anions. Using their optimum conditions, these researchers produced ingots with levels of uranium near the levels of the metal prior to contamination and melting.

In another study of the effect of slag basicity, Chinese researchers Ren, Liu, and Zhang ${ }^{20}$ conducted 100 gram melt tests in order to determine suitable flux composition and process parameters for the effective removal of uranium from copper, nickel, and mild steel. Results indicated that decontamination efficiency is related to slag basicity. The blast furnace slag produced by the Taiga Steel Plant had a composition of $38.1 \% \mathrm{SiO}_{2}$, $41.4 \% \mathrm{CaO}, 3.8 \% \mathrm{MgO}, 2.6 \% \mathrm{Fe}_{2} \mathrm{O}_{3}$, and $14.1 \% \mathrm{Al}_{2} \mathrm{O}_{3}$ and had a basisity of approximately 1.1 . Using this blast furnace slag as a base, slag chemistry was varied from a composition with a bacisity of 0.25 to a composition having a bacisity of 1.95 . Optimum decontamination was achieved with a flux having a basicity of 1.1.

In 1992, Westinghouse Idaho Nuclear Company was directed by the DOE to investigate the melt refining of contaminated stainless steel. Research performed at the

${ }^{17}$ Uda, T., Iba, H., Tsuchiya, H., "Decontamination of Uranium-Contaminated Mild Steel by Melt Refining" Nuclear Technology, Vol.73, April 1986.

${ }^{18}$ Abe, M., Uda, T., and Iba, H., "Melt Refining Method for Uranium-Contaminated Steels and Copper," Waste Management 85, proceedings of the Sumposium on Waste Management at Tucson, Arizona, Mar. 24-28, No. 3, p.375, 1975a.

${ }^{19}$ Turkdogan, E.T., Physical Chemistry of High Temperature Technology, Academic Press, New Youk , p. 140. 1980.

${ }^{20}$ Ren, X.W., Liu, W.C., Zhang, Y., "Melt Refining of Uranium Contaminated Copper, Nickle, and Mild Steel," Proceedings of the International and Topical Meeting on Nuclear and Hazardous Waste Management, Spectrum 94, Atlanta, GA, August 14-18, ANS. 
Montana College of Science and Technology ${ }^{21}$ consisted of multiple small scale (two pound) air induction melts of stainless steel which had been doped with cerium, lanthanum, and neodymium to simulate the presence of radionuclides. This research showed that the ability of a slag to collect contaminants from metal is time and temperature dependent. Decontamination efficiency was also shown to be related to slag chemistry.

\section{A2.3 Technology Utilization}

The European community has been active in treating radioactive scrap by melting techniques. The French published a study of the melting of portions of a rejected carbon steel heat exchanger from the Chinon A power plant. ${ }^{22}$ The activity of the incoming metal was between 10 and $20 \mathrm{mCi}$ per metric ton. The purpose of the test was to determine the behavior and final distribution of radionuclides after melting as well as to evaluate the potential contamination of the surroundings due to the melting and casting processes. The melting furnace used was a refractory lined graphite electric arc furnace of 4 to 5 metric ton capacity equipped with a mobile hood for fume capture. The furnace type and dimensions necessitated the size reduction of the contaminated metal into sections less than one meter in length. A total of 221 man-hours was necessary for this sizing operation. After melting, the furnace was tilted and the metal was poured into molds to produce castings with a combined weight of $3660 \mathrm{~kg}$, The weight of the slag was $200 \mathrm{~kg}$ and that of the dust was $30 \mathrm{~kg}$. The activity of each of the products was measured and $76 \mu \mathrm{Ci}$ was found in the ingots, $217 \mu \mathrm{Ci}$ in the slag, $148 \mu \mathrm{Ci}$ in the filter dust, and $38 \mu \mathrm{Ci}$ in the molding sand. Radiation checks in the vicinity of the furnace during operation revealed that the atmospheric activity did not exceed the maximum permissible level for public exposure of $10 \mathrm{pCi} / \mathrm{m}^{3}$. The report concluded that the dose rates are sufficiently insignificant to permit the operation of a 4000 metric ton operation in complete safety.

Jacquet-Francillon and co-researchers ${ }^{23}$ reported the development of a cold crucible induction melting operation designed to melt contaminated zircalloy and stainless steel hulls from the pilot nuclear facility at Marcoule. An industrial scale facility designed to process 15 ingots/year was scheduled to begin production in 1993. In addition the French have begun arc furnace melt consolidation for the treatment of ferrous materials recovered from the dismantling of the $\mathrm{CO}_{2}$ systems from the graphite moderated, $\mathrm{CO}_{2}$ cooled plutonium production and power generation reactors at Marcoule. The three phase, 15 tonne arc furnace has been operating since April 1992. By April 1993, an estimated 2580 tonnes of cast iron had been produced for reuse within the nuclear industry. ${ }^{24,25}$

${ }^{21}$ Worcester, S.A., Twidwell, L.G., Paolini, D.J., Weldon, T.A., Mizia, R.E. (Ed.)

"Decontamination of Metals by Melt Refining/Slagging, An Annotated Bibliography:

Updiate on Stainless Steel and Steel," INEL-95/0123, INEL-DOE, January, 1995.

${ }^{22}$ Lacroix, J.P.; Tailliez, M. "STMI's Industrial Experience in Low Activity Steel Waste Processing by Melting," Waste Mangement 86, 3, R.G. Post (ed.) 1986, pp. 547-552.

${ }^{23}$ Jacquet-Francillon, N., Jouan, A., Moncouyoux, Sombret, C., "Melting: A Promising Technique for Processing Metallic Decladding Materials from Irradiated Nuclear Fuels", ICCM 91, Bombay, India, 1991.

${ }^{24}$ Peulve, J., "Treatment of Dismantled Materials by Fusion," Techno-992-022, 1992.

${ }^{25}$ Peulve, J., et. al., "Dismantiling of Nuclear Facilities Scrap Steel Management of G2 and G3 Reactors at Marcoule," UDIN, Commissarit A L'Energie Atomique, Marcoule ie Apr. $16,1993$. 
Melt consolidation of ferrous scrap from dismantling and backfitting nuclear power plants began at the Siempelkamp foundry in Krefeld, Germany in $1984 .{ }^{26}$ While the first melts were performed using a modified 20 tonne coreless induction furnace, a new facility became operational in 1990 . This facility consists of a 3.2 tonne $300-500 \mathrm{~Hz}$ coreless induction furnace with a melting capacity of 2 tonne/hr. The furnace facility is equipped with a fume system which provides negative pressure to the melting enclosure. ${ }^{27}$ This facility was used to melt 500 tonnes of steel scrap from decommissioning the Gundremmingen Unit A (KRB A) nuclear power plant. Mies ${ }^{28}$ reports that samples taken from remelted scrap are within permissible levels of activity, that the slag is disposed of at normal industrial waste facilities, and the filter dust is stored as low level waste.

British Steel Corporation ${ }^{29}$ conducted a study to determine the practicality of releasing properly treated and characterized RSM to commercial electric furnace operations. The scrap used in this study was composed of contaminated steel from three different reactor systems which was mixed in various ratios with uncontaminated steel. The study consisted of 16 heats, six of which were melted in $50 \mathrm{~kg}$ or 0.5 tonne induction furnaces and ten of which were melted in a 5 tonne electric arc furnace. The radionuclides of interest were ${ }^{60} \mathrm{Co},{ }^{134} \mathrm{Cs}$, and ${ }^{137} \mathrm{Cs}$. Because of its chemical similarity to iron, the cobalt consistently partitioned to the steel castings while the cesium was captured in the slag and the fume. The partitioning of cesium between slag and fume was reported to be a function of the melting technique, the slag composition and the type of scrap melted. After analysis, all the ingots produced in this study were diluted in 300 tonne basic oxygen furnaces to less than 10-5 $\mu \mathrm{Ci} / \mathrm{g}$. In a continuation of this work, experiments were undertaken in which europium $\left({ }^{152} \mathrm{Eu}\right.$ and $\left.{ }^{154} \mathrm{Eu}\right)$ contaminated steel was melted in a $500 \mathrm{~kg}$ induction furnace as well as in a 3 tonnne arc furnace. It was found that the europium was contained wholly in the slag under both oxidizing and reducing conditions and that none was detectable in either the steel or the off gasses. The conclusion drawn from this research was that, although the process could be operated within published safety criteria, the cost of controlling and monitoring the scrap would out weigh its value. This research program was concluded in 1988 with no plans of future work. ${ }^{30}$

In Sweden, radioactive scrap metal of Swedish and German origin was melted at Studsvik AB. By the end of 1988 , over 400 tonnes of low activity scrap metal had been melted, of which approximately $90 \%$ was carbon steel and the remainder was stainless steel. The induction furnace employed has a capacity of 1.5 tonne/hr. Analytical results

${ }^{26}$ Sappok, M., Tarcza, G.A., "Results of Metallic Waste Treatment by Melting,"

Siemplekamp Giesserei GmbH \& Co., Germany; CONF-874048 Vol. 1, Westinghouse Hanford, Oct., 1987.

${ }^{27}$ Sappok, M., Rettig, G., "Results of Melting Large Quantities of Radioactive Metallic Scrap," Proceedings of the International Topical Meeting on Nuclear and Hazardous Waste Management, Spectrum “92," American Nuclear Society, La Grange Park, Illinois, pp.120, 1992.

${ }^{28}$ Mies, H.P., Stang, W., "Decommissioning of Nuclear Power Plant Gundremmingen Unit

A,"Kernkraftwerke Gundremmingen Betriebsgesellschaft, Germany, 1991.

${ }^{29}$ Gomer, C.R., Lambley, J.T., "Melting of Contaminated Steel Scrap Arising in the Dismantling of Nuclear Power Plants," EUR-10188, Commission of the European Communities, 1985.

${ }^{30}$ Harvey, D.S., "Melting of Contaminated Steel Scrap from Decommissioning," or Advances in Ceramics, Vol. 20. Nuclear Waste Management II, 1986 Decommissioning of Nuclear Installations-1990, Brussels, Pfulgrad, et. al. editors, 1990a. 
showed that $\mathrm{Co}, \mathrm{Mn}, \mathrm{Zn}, \mathrm{Ag}$, and $\mathrm{Sb}$ remained in the steel while $\mathrm{Cs}$ partitioned to the slag and dust. ${ }^{31}$

In Japan, large scale reactors are scheduled for shutdown and dismantling in order to use the sites for new reactors. Therefore, establishing rational methods for reducing the amount of low level waste has had high priority due to limited area for a final repository. Decontamination technology for use in decommissioning the Japan Power Demonstration Reactor (JPDR) has been the object of research by the Japan Atomic Energy Research Institute (JAERI). ${ }^{32}$ While several chemical and decontamination methods have been developed and studied, metal melting is viewed as a simpler way to facilitate the reuse of metal wastes from nuclear facilities. The objectives of tests performed by JAERI have been to investigate and assess the behavior of radionuclides during melting and casting and their influence on the working environment. The radioactive metal melting test program began by designing test equipment in 1987. Installation of the equipment was completed by the end of March $1990 .^{33}$ The melting equipment includes a $500 \mathrm{~kg}$ high frequency induction furnace equipped with a ring hood which may be made air tight during melting. Melting and casting equipment are enclosed in a steel chamber which is kept at a slightly negative pressure to minimize the spread of radionuclides. Tests included a study of both stainless and carbon steel melting. Following equipment installation, cold tests on non-radioactive steels were performed. By September 1991, six melts of radioactive metal recovered from JPDR had been conducted. Late in 1991, radioactive tracer tests were begun using gamma emitting tracers that imitate the nuclides found in contaminated material from light water reactors, such as ${ }^{54} \mathrm{Mn},{ }^{60} \mathrm{Co},{ }^{65} \mathrm{Zn},{ }^{85} \mathrm{Sr}$, and ${ }^{137} \mathrm{Cs}$. In addition to these radionuclides, ${ }^{63} \mathrm{Ni}$ was used as a beta emitting radionuclide and tests were conducted separately. Experimental parameters controlled in the tests were the condition of the radioactivity (activated, surface contaminated, or artificially added tracers), type of additives or flux, and melting temperature. Melting was carried out in the range $1350-1650^{\circ} \mathrm{C}$. Slag properties were varied by controlling the ratio of $\mathrm{CaO} / \mathrm{SiO}_{2}$ in the flux. The assessments for each test included the radiation dose within the work place, radionuclide transfer from charge material to ingot, slag, dust, and offgas, and the resultant radioactivity distribution within an ingot. As of 1992, eleven heats had been melted and cast. Two heats of 304 stainless steel and four heats of carbon steel were made up of scrap from the JPDR reactor, and two heats of stainless steel and three heats of carbon steel were made up of uncontaminated scrap to which radioactive tracers had been added. The radioactive tracer ingots were sectioned in three places and samples were taken across each section to obtain the edge to center distribution of the tracers. Analysis revealed that $99.5 \%$ of the cobalt, $91 \%$ of the manganese, and $75 \%$ of the zinc remained in the ingot and were found to be uniformly distributed. None of the strontium or the cesium was found to be present in the ingots. Slag analysis showed that none of the cobalt was present, while $1 \%$ of the zinc, $7 \%$ of the manganese, $39 \%$ of the cesium, and $73 \%$ of the strontium were present. Accuracy of the fume analysis was questioned because the lack of closure (7\% of the zinc, $27 \%$ of the

${ }^{31}$ Menon, S., Hernborg, G., Andersson, L., "Melting of Low-Level Contaminated Steels," Decomissioning Nuclear Installations-1990, Studsvik AB, Sweden, p. 497, 1990.

${ }^{32}$ Fujiki, K., Hirabayashi, T., Kanazazawa, K., Yasunaka, H., "Decontamination and Melting Test for Metal Waste in JPDR Decommission Project-Toward recycling of LLW," Proceedings Waste Management, Tucson, AZ, USA, 1991a.

${ }^{33}$ Nakamura, H., Fujiki, K., "Radioactive Metal Melting Test at Japan Atomic Energy Research Institute," Japan Atomic Energy Research Institute, 1992. 
strontium, and $23 \%$ of the cesium) could have been caused by condensation of the fume before it reached the sampling location. ${ }^{34}$

In the United States, RSM melt decontamination is being approached with renewed interest in recent years. Scientific Ecology Group, Inc. (SEG) ${ }^{35}$ operates a 20 ton $7200 \mathrm{kw}$ induction melting furnace equipped with a dedicated fume hood. The furnace operates within a building equipped with HEPA filtered ventilation. During one melting campaign, 2735 tons of carbon steel shielding blocks were produced and during another, 2200 tons of carbon steel rolling mill feed stock was melted and cast into shield blocks for nuclear operations. ${ }^{36}$

While many countries have recently begun melting of radioactive scrap metal for densification and limited reuse for low technology applications, there is, as yet, no plan in place for the recycle of specialty metals for high technology applications. The stockpile of contaminated metals in the United States is composed of valuable alloys which could be decontaminated and reused for nuclear related applications with their original properties intact. The alternative is the costly disposal and long term monitoring of these materials. The choice to dispose of contaminated strategic metals leads to the use of virgin materials for use in nuclear applications. These virgin materials will become contaminated, adding to the problem. If, however, the alternative of decontamination and recycle is chosen, storage costs are greatly reduced and the need for materials to be used in present or future nuclear applications is met.

\footnotetext{
${ }^{34}$ Nakamura, H., Kanazawa, K., Sato, T., Yamate, K., Fujiki, K., "Fundamental Research on Melting of Radioactive Metal Materials," Japan Atomic Energy Research Institute, Shirakata-shirane, Tokaimura, Ibaraki-ken, 319-11, Proceedings of the International Topical Meeting on Nuclear and Hazardous Waste Management, Spectrum 94, Atlanta, GA, August 14-18, ANS.

${ }^{35}$ Scientific Ecology Group, Inc., (SEG) SEG Commercial Phamplet on "Metal Processing," and Industrial Portfolio, Scientific Ecology Group P.O. Box 2530, 1560 Bear Creek Road, Oak Ridge, TN 37830, 1993.

${ }^{36}$ Worcester, S.A., Twidwell, L.G., Paolini, D.J., Weldon, T.A., Mizia, R.E. (Ed.)

"Decontamination of Metals by Melt Refining/Slagging, An Annotated Bibliography: Updiate on Stainless Steel and Steel," INEL-95/0123, INEL-DOE, January, 1995.
} 
SAND 96-0902 Distribution

$\begin{array}{lllll}1 & \text { MS } 1435 & \text { Harry Saxton } & \text { Org. } 1800 \\ 2 & \text { MS } 0727 & \text { Thomas Sanders } & \text { Org. 6406 } \\ 10 & \text { MS } 1134 & \text { Eric Schlienger } & \text { Org. 1833 } \\ 2 & \text { MS } 1134 & \text { Joanna Buckentin } & \text { Org. 1833 } \\ 2 & \text { MS } 1134 & \text { Brain Damkroger } & \text { Org. 1833 } \\ 1 & \text { MS } 9018 & \text { Central Technical Files } & \text { Org. 8523-2 } \\ 5 & \text { MS } 0899 & \text { Technical Library } & \text { Org. 4414 } \\ 1 & \text { MS } 0619 & \text { Print Media } & \text { Org. 12615 } \\ 2 & \text { MS } 0100 & \text { Document Processing for DOE/OSTI } & \text { Org. 7613-2 }\end{array}$

